CENTRE for ECONOMIC

$\begin{array}{lllllllllll}P & E & \mathrm{~F} & \mathrm{O} & \mathrm{R} & \mathrm{M} & \mathrm{A} & \mathrm{N} & \mathrm{C} & \mathrm{E}\end{array}$

CEP Discussion Paper No 1394

December 2015

\title{
The Youngest Get the Pill: Misdiagnosis and the Production of Education in Germany
}

\author{
Hannes Schwandt \\ Amelie Wuppermann
}




\begin{abstract}
Attention Deficit/Hyperactivity Disorder (ADHD) is a leading diagnosed health condition among children in many developed countries but the causes underlying these high levels of ADHD remain highly controversial. Recent research for the U.S., Canada and some European countries shows that children who enter school relatively young have higher ADHD rates than their older peers, suggesting that ADHD may be misdiagnosed in the younger children due to their relative immaturity. Using rich administrative health insurance claims data from Germany we study the effects of relative school entry age on ADHD risk in Europe's largest country and relate the effects for Germany to the international evidence. We further analyze different mechanisms that may drive these effects, focusing on physician supply side and demand side factors stemming from the production of education. We find robust evidence for school-entry age related misdiagnosis of ADHD in Germany. Within Germany and internationally, a higher share of misdiagnoses are related to a higher overall ADHD level, suggesting that misdiagnoses may be a driving factor of high ADHD levels. Furthermore, the effects in Germany seem to be driven by teachers and parents in an attempt to facilitate and improve the production of education
\end{abstract}

Keywords: ADHD, misdiagnosis, age cut-off, education JEL codes: I1; I2; J1

This paper was produced as part of the Centre's Wellbeing Programme. The Centre for Economic Performance is financed by the Economic and Social Research Council.

The authors would like to thank Joerg Baetzing-Feigenbaum, Anna Chorniy, Ramona Hering, Mandy Schulz as well as workshop and seminar participants in Mannheim, the Max Planck Munich and Humboldt University Berlin for comments and Ingrid Hagele and Katrin Poschen for excellent research assistance. A previous working paper version of this paper has been published in German under the title "Zusammenhang zwischen ADHS-Diagnose- und Medikationsprävalenzen und dem Einschulungsalter" at http://www.versorgungsatlas.de/.

Hannes Schwandt, Assistant Professor at University of Zurich and Associate at Centre for Economic Performance, London School of Economics. Amelie Wuppermann Junior Professor in Microeconometrics at University of Munich.

Published by

Centre for Economic Performance

London School of Economics and Political Science

Houghton Street

London WC2A 2AE

All rights reserved. No part of this publication may be reproduced, stored in a retrieval system or transmitted in any form or by any means without the prior permission in writing of the publisher nor be issued to the public or circulated in any form other than that in which it is published.

Requests for permission to reproduce any article or part of the Working Paper should be sent to the editor at the above address.

(c) H. Schwandt and A. Wuppermann, submitted 2015. 


\section{Introduction}

ADHD has been rising dramatically among school children over the past decade and it is now the leading diagnosed health condition in Germany and other Western countries like the U.S. ADHD treatment has the potential to help children with ADHD - as well as their peers - focus in class and reduce risky behavior outside of school (Aizer 2008; Dalsgaard, Nielsen, and Simonsen 2014; Chorniy and Kitashima 2014) . But the psycho-active medication also alters the brain function and might have negative short- and long-term effects on human capital development (Gould et al. 2009; Cascade, Kalali, and Wigal 2010; Currie, Stabile, and Jones 2014). It is therefore an important question whether the increases in the diagnosis of ADHD are due to an actual deterioration in mental health among recent generations of children or whether some of it is driven by an increase in cases of misdiagnosis. And if there is misdiagnosis, it is important to know which factors are driving it. For example, it could be driven by doctors who overtreat in response to a more competitive health care environment or by teachers and parents who seek to improve the teaching environment and children's educational outcomes?

One way to identify potential cases of ADHD misdiagnosis in observational health care data is to study ADHD rates around school entry cutoff dates (Elder 2010; Evans, Morrill, and Parente 2010). Children who are born right before the cutoff date will enter school a year earlier than those born right after the cutoff and will be almost a year younger than the oldest (those born right after the cutoff in the year before) in their class. Relatively younger students are less mature and often less disciplined than their older classmates. But being born right before a cutoff date should not be correlated with the risk of ADHD, a largely genetically determined condition (Faraone et al. 2005; Tarver, Daley, and Sayal 2014). Hence, jumps in ADHD prevalence between cohorts born just before and just after school entry cutoff dates are an indicator of misdiagnosis. Previous studies have found such evidence of misdiagnosis around the age cutoffs for the U.S., Canada, the Netherlands, Sweden, and Iceland (Elder 2010; Evans, Morrill, and Parente 2010; Morrow et al. 2012; Halldner et al. 2014; Krabbe et al. 2014; Zoëga, Valdimarsdóttir, and Hernández-Díaz 2012), while no effects have been found for Denmark (Dalsgaard et al. 2012; 
Pottegård et al. 2014). Overall, drivers behind the ADHD jumps around cutoff dates remain uncertain, though plausible explanations have been proposed (e.g. Dalsgaard et al. 2012).

In this paper we use data on more than 7 million German children to analyze ADHD rates around school entry cutoff dates in unprecedented detail for one of the largest countries of the developed world. The data is based on the universe of outpatient health insurance claims for publicly insured children (about $90 \%$ of all children in Germany) over the years 2008-2011. The German education system is organized at the level of 16 states and there are various different cutoff dates. The variation in cutoff dates together with the large sample size provides us with sufficient statistical power to estimate jumps around age cutoffs non-parametrically and conduct subgroup analyses across cohorts, ages, gender and districts. We further merge information on regional physician supply, schooling environment and parental background to our data in order to investigate factors associated with the cutoff jumps.

We find large jumps in ADHD rates around cutoff dates, amounting to $22 \%$ for children aged 9 to 13 ( 1 percentage point at a baseline ADHD rate of about 5\% in that age range). These jumps occur at different months across states in accordance with the different cutoff dates, indicating that the jumps in prevalence rates represent misdiagnoses rather than actual differences in children's health which are unlikely to be spuriously correlated with the different cutoff dates across states. The cutoff dates also impact medical treatment of ADHD. Moreover, there is no comparable pattern for the prevalence of diabetes or for hay fever, a condition with similar prevalence rates as ADHD. This indicates that jumps in ADHD rates around cutoffs are not driven by a general effect of relative age on physicians' diagnosing behavior but specific to ADHD. There is also no effect of relative age on injury rates among children without ADHD diagnosis. This finding supports the notion that misdiagnoses around age cutoffs are driven by overdiagnoses among younger students rather than underdiagnoses among older students who should - if lackig required ADHD treatment - suffer from higher injury rates.

Misdiagnosis rates around cutoff dates are strongly correlated with the average level of ADHD rates, both across regions as well as within regions over time. Remarkably, this relationship of 
misdiagnosis rates and average ADHD levels is very similar to the relationship that we find when comparing the estimates across the countries that have been analyzed in the existing literature. This result suggests that misdiagnosis rates around cutoff dates are an explanatory factor of the high ADHD rates observed in many countries, perhaps proxying for a general tendency to overdiagnose ADHD. An important question therefore is: Which factors are driving these misdiagnoses?

Merging the ADHD data to district level characteristics we find that jumps in ADHD prevalence around the cutoff dates are weakly negatively related to the density of pediatricians, psychiatrists or psychologists. This finding rejects the hypothesis that a more competitive health care environment characterized by a higher physician density induces physicians to overdiagnose. If anything a larger supply of physicians leads to a decrease in misdiagnoses. However, we do find that misdiagnosis rates within regions increase over time with the share of foreign students and class sizes as well as with a region's average income and education. These results suggest that jumps might be driven by teachers and parents in an attempt to facilitate and improve the production of education. ${ }^{1}$ On the teacher side, the relative immaturity of younger students might become more apparent in difficult schooling environments and teachers might be more inclined to interpret disruptive behavior as pathological. Well-educated parents, on the other hand, might be particularly concerned about their children's education and thus try to counteract the possible disadvantages in performance if their children are particularly young for their grade level. Whether such potential ADHD overtreatment can actually lead to improvements in educational outcomes for a misdiagnosed child or for its peers remains an open question.

Previous studies have found a wide range of estimates for jumps in ADHD rates around school entry age cutoffs, ranging from zero in Denmark (Dalsgaard et al. 2012) to 50\% in Iceland (Zoëga et al. 2012) and the U.S. (Elder 2010; Evans et al. 2010). Our estimates of about $20 \%$ are in the mid-range and closest to the cutoff jumps found in Canada (Morrow et al. 2012). We show that this cross-country variation in cutoff jumps is highly predictive of a country's average ADHD level and that this positive

\footnotetext{
${ }^{1}$ Both teachers and parents can influence ADHD diagnoses. As in the U.S., ADHD diagnosis guidelines in Germany require that doctors take parents' and teachers' assessment of a child's behavior into account.
} 
relationship is remarkably linear. Moreover, it is very similar to the relationship observed across German states. In other words, countries and regions with strong jumps in ADHD rates around age cutoffs have also higher overall ADHD rates, perhaps because the cutoff jumps proxy for a general tendency to misand overdiagnose ADHD. This finding does not only unify the wide range of estimated cutoff jumps from previous studies, it also underlines the importance of the literature on cutoff jumps to help the understanding of the high ADHD rates in the Western world.

Whether jumps in ADHD rates around age cutoffs represent misdiagnoses and --in case they do-whether they are driven by over- or underdiagnoses is a central question in the literature that has not yet been explored extensively. Elder (2010) provides evidence that jumps represent misdiagnoses, based on the comparison of how teachers and parents assess students' behavior. However, in principle these misdiagnoses might not only stem from overdiagnoses (false positives) among younger students but could also be driven by underdiagnoses (i.e. false negatives) among older students (Evans, Morrill, and Parente 2010). Our analysis of injury data supports the notion that these misdiagnoses actually represent false positives.

Another central question of the literature is which factors drive the observed jumps in ADHD rates around cutoff dates. Dalsgaard et al. (2012) suggest that one factor leading to low misdiagnosis rates in Denmark could be the supply of physicians with good diagnostic skills. In Denmark only specialist physicians are allowed to diagnose ADHD and these doctors might be less prone to misdiagnoses. Our findings are in line with the hypothesis of Dalsgaard et al. (2012). We find that a greater per-capita density of those doctors who are typically diagnosing ADHD in Germany is associated -- if anything -- with lower misdiagnosis rates and this is also true when looking at changes over time.

Elder (2010) provides evidence for the U.S. -- with high misdiagnosis rates at the other end of the ADHD spectrum -- that teachers might be a driving force behind cutoff jumps. Our finding of increasing misdiagnoses rates in areas with increasing class sizes and rising shares of foreign students is in line with Elder's (2010) hypothesis that teachers' demand for ADHD medication of their students might be part of 
the story. However, we find that parents may also play a role as areas with rising shares of employees with higher education and increasing labor income have increasing rates of misdiagnoses.

The paper proceeds as follows: Section 2 discusses the school and health care system in Germany. Section 3 provides an overview of our data and methods. Section 4 presents the results, and a conclusion follow in Section 5.

\section{Germany's school and health care system}

\subsection{School system}

School policy is almost exclusively legislated at the level of the 16 states in Germany. ${ }^{2}$ In all states, children generally have to start school in the fall of the year in which they have turned six by a specific date - the school entry cutoff date. Historically, June 30 was the cutoff date in all states. While the cutoff is the general rule, there are exceptions: All children are examined by a government physician before they are allowed to enroll in school. Children who are not considered "ready for school" although they meet the age cutoff are supposed to wait another year. At the same time, children can enter school although they do not meet the age cutoff following parental application and the school readiness exam. Compliance with the age cutoff is high in Germany: Between 2000 and 2011, on average about $86 \%$ of children entered school according to the cutoff date (own calculations based on Federal Statistical Office, 2014.) As a comparison, the compliance rate in Denmark is about 60\% (Dalsgaard et al. 2012) while it ranges from $70 \%$ (Elder 2010) to a mere 35\% (Evans, Morrill, and Parente 2010) in the U.S.

In order to decrease the school starting age in Germany, states started to push back the cutoff date from 2003 onwards. As Appendix Table 1 indicates, 8 of the 16 states have since changed their cutoff date. One state (Thuringia) only postponed the cutoff date by 1 month to July 31 . Others postponed it further, often in several steps. In Baden-Wuerttemberg, for example, the cutoff date was postponed to July

\footnotetext{
${ }^{2}$ See Lohmar and Eckhardt (2013) for a general overview over the German education system.
} 
$31^{\text {st }}$ for children entering school in 2005 , to August $31^{\text {st }}$ for children entering school in 2006 , and to September 30 for children entering school in 2007. The most extreme policy change occurred in Berlin where the cutoff date was moved from June 30 for children entering school in 2003 to December $31^{\text {st }}$ for those entering in 2004. As the sizes of the entering cohorts necessarily vary in years in which the cutoff dates are shifted, we exclude cohorts who enter school in reform years from the following analyses.

\subsection{Health care system}

In this paper, we focus on children covered by social health insurance (SHI) in Germany. Roughly $90 \%$ of the German population is covered in the SHI. Most employees and their families are mandatorily enrolled in the SHI. Only few individuals with higher socio-economic status (SES) - the self-employed, employees with labor income higher than a specific yearly-defined threshold, and civil servants - can decide to optout of this system. By focusing on children insured in the SHI, we thus study the majority of German children, disregarding mainly those whose parents have higher SES.

Within the SHI, children are covered free of charge on their parents' policy. Furthermore, no copayments or coinsurance apply to most care that children receive (doctor visits, hospital stays, and prescription drugs). This includes diagnoses and treatment of ADHD. Any physician registered with the SHI can generally diagnose - and get reimbursed for the diagnosis of - ADHD. The majority of children with ADHD, however, have a diagnosis from specialists, such as pediatricians (51\%), or child and youth psychiatrists (28\%) (Grobe, Bitzer, and Schwartz 2013, p. 173). The largest group of diagnoses from nonspecialists is made by primary care physicians accounting for $36 \%$ of diagnoses. ${ }^{3}$ Mainly two different drugs are used to medically treat ADHD among children in Germany: Methylphenidate and Atomoxetine. In Germany, both of these are only approved for the treatment of ADHD. Until the end of 2010, medical treatment for ADHD could be prescribed by any registered physician. Since 2011, however, only specialists (including pediatricians, neurologists, and psychiatrists) are allowed to prescribe ADHD

\footnotetext{
${ }^{3}$ However, Grobe et al. 2013 do not distinguish first from follow-up diagnoses. The diagnoses made by primary care physicians may thus reflect follow-up treatment based on initial diagnoses made by specialists.
} 
medication. Since then primary care physicians can only prescribe ADHD medication as a follow-up prescription (e.g. Hering et al. 2014).

According to medical guidelines published by the association of German Child and Youth Psychiatrists (German Association for Child and Youth Psychiatry et al. 2007), doctors should base their diagnosis on an examination of the child herself, as well as information on the child's behavior in other settings (e.g. at home and at school) from parents and from third parties (e.g. teachers). This information is typically elicited using parents and teacher questionnaires. For an ADHD diagnosis, the typical symptoms of hyperactivity, inattentiveness, and impulsivity have to occur repeatedly in at least two different settings for at least six months, have to be abnormally high for the developmental stage of the child, and should have first occurred before the age of six.

\section{Data and Methods}

\subsection{Data}

The analyses presented in this paper rely on one main data source: administrative medical claims records from all physicians registered with the SHI, covering the universe of outpatient visits of all children insured in the SHI aged 4 to 14 for the years 2008 through 2011. The data are collected at and provided by the Zentralinstitut fuer die Kassenaerztliche Versorgung in Deutschland (ZI). ${ }^{4}$ For each of the years 2008-2011, the data cover information on roughly 7.2 million children with all their outpatient visits, diagnoses of different conditions (ICD 10 codes) and timing of the visits. The data further contain information on the children's sex, month and year of birth, and current place (state and district) of residence. In addition, we make use of a separate dataset collected at the ZI that contains information on all prescription drugs received for the same children. The two datasets are not generally linkable on the individual level.

\footnotetext{
${ }^{4}$ For a description of the data in German, see http://www.versorgungsatlas.de/der-versorgungsatlas/angewandtemethoden/
} 
Using these data, we construct prevalence measures of ADHD diagnosis and ADHD treatment, as well as diagnosis prevalence of other diseases (hay fever and diabetes) for each birth cohort in each of the 412 German districts. We define as birth cohort all children born in the same month and year. For each birth cohort in each of the 412 German districts and each data year, we generally define ADHD diagnosis prevalence as the number of children with at least one ADHD diagnosis in two different quarters ${ }^{5}$ during the data year relative to the overall number of children in that birth cohort and district.

Diagnoses prevalence of diabetes and hay fever are constructed similarly, except that only one quarter with a diagnosis is required for hay fever to take account of its seasonal pattern. As children's sex is known in the data on outpatient visits, we are also able to construct these measures by sex. Using the data on prescription drugs, we construct the fraction of children treated with either Methylphenidate or Atomoxetine - two drugs only approved for treatment of ADHD in Germany - by dividing the number of children who receive medical treatment in a given year by the overall number of children in that birth cohort.

A caveat with this data source is that we only observe children if they visited a doctor at least once or received some prescription drugs in a given year. As not all children insured in the SHI necessarily have at least one doctor visit or prescription each year, our measures of diagnosis prevalence may overestimate the true prevalence. We therefore compare our measures to ADHD rates across several age groups that are available from administrative data of Germany's second largest health insurance provider (Barmer GEK). The latter data include information on all children with this insurance provider, independent of whether they have visited a doctor. Our ADHD prevalence estimates align closely with the rates from Barmer GEK (see Appendix A).

\footnotetext{
${ }^{5}$ ADHD is coded according to the International Classification of Disease (ICD) 10 diagnostic manual. We rely on at least one valid diagnosis in two quarters of the year to identify diseases from the claims. This restriction increases the probability to identify only children as ADHD patients who are actually treated for the condition.
} 
We augment the administrative health claims data with information at the district level on the supply of physicians, socio-economic information, as well as information on the school environment from different data sources, as listed in Appendix Table 2.

Table 1 provides descriptive statistics based on the claims data. Pooling the observations from all four years (2008-2011) and across all 16 German states, we have a sample of roughly 29 million children that are on average 9 years old at June 30 of the given data years. Among them $3.8 \%$ are diagnosed with ADHD, and $2.7 \%$ receive medical treatment for ADHD. Diagnosis prevalence of hay fever is a little higher than ADHD (5.8\%), while only $0.3 \%$ of children are diagnosed with diabetes. As we restrict several of the following analyses to the states only that had no reforms in cutoff dates, Table 1 shows descriptive statistics for all states and only for those that had no reforms. Although only roughly $24 \%$ of all children live in states that did not enact reforms in cutoff dates, the descriptive statistics are similar in these states as column (2) indicates.

Columns (3) to (12) show how these outcomes vary by grade level. We assign children to school grades based on their month of birth relative to the cutoff date that applied in the year they were supposed to enter school in their state of residence. For example, -1 indicates that children should enter school in the year following the data year if they comply with the school entry cutoff date in their state of residence. Similarly, $1^{\text {st }}$ indicates that children should have entered first grade in the data year if they complied with the cutoff date. For both ADHD diagnoses and medical treatment, Table 1 shows a strong increase in the prevalence from pre-school to grade 4. While ADHD diagnosis prevalence starts to level off and declines slightly after grade 4 , the prevalence of ADHD treatment further increases until $6^{\text {th }}$ grade and then starts declining. Hay fever and diabetes also show increases in diagnosis prevalence with assigned grade, but the trend does not reverse after $4^{\text {th }} / 6^{\text {th }}$ grade.

\subsection{Methods}

To study possible misdiagnoses of ADHD, we follow the earlier literature and document how ADHD diagnosis and treatment are affected by students' (assigned) relative age as compared to their classmates. 
Diagnoses of ADHD are highly subjective (Furman 2005; Bruchmüller and Schneider 2012) and medical guidelines and diagnostic criteria such as DSM-IV and ICD 10 used for diagnoses in Germany state that symptoms have to persist to a degree inconsistent with a child's developmental level. If a child's classmates are used to define the normal behavior for the developmental level, younger children in class may be misdiagnosed with ADHD if they are behaving less maturely than the "norm" in class due to their younger age. Such systematic misdiagnosis would imply a negative relationship of relative age and ADHD prevalence. However, the correlation of relative age and ADHD prevalence in observational data might not be informative because the age at which children enter school might itself be a function of their behavior. In Germany children can only enroll in school once their readiness for school has been evaluated by a government physician. The children who enter school very young are likely those who are considered advanced for their age - and thus have lower chances of showing ADHD symptoms - while children who are retained and then enter school older are likely behind for their age - with stronger ADHD symptoms. A simple correlation between relative age in grade and ADHD prevalence may thus reflect reverse causality rather than the effect of a child's relative age position within a grade.

School entry cutoff dates provide a plausibly exogenous source of relative age for grade that allows for solving the described endogeneity problem. The idea behind this is to only use the variation in relative age in grade that stems from the difference of children's birth dates relative to the cutoff date, i.e. the (assigned) relative age that children would have, had everyone complied with the cutoff. Under the assumption that children's birth dates relative to the cutoff date are not related to health for other reasons than the resulting relative age in grade, this variation allows to identify the effect of relative age on health outcomes (see also Elder 2010; Evans, Morrill, and Parente 2010; Dalsgaard et al. 2012).

This identifying assumption would be violated if children born in different months differed systematically in their health for other reasons than their relative age in grade. Currie and Schwandt (2013) and Schwandt (2015) show that mothers select into conception months according to their socioeconomic status and that the pregnancy season also has a direct effect on infant health, e.g. via seasonal 
influenza waves. Parents could also time conceptions in correspondence with the cutoff dates. This means there might be seasonality in children's baseline health (or health at birth) and some of it could be spuriously correlated with the distance from the cutoff. To test for such spurious relationships we analyze other health outcomes such as hay fever or diabetes, which correlate with children's baseline health but which should not be affected by relative age in grade. Moreover, we analyze states that reformed the cutoff dates. If the jumps in ADHD rates move with the cutoff dates, this shows that they are not driven by a general seasonal pattern in baseline health. These reforms could also not be anticipated half a decade in advance, so that parents could not time their conceptions accordingly even if they intended.

Given that the identifying assumption is rather plausible, differences in ADHD prevalence across birth months around the cutoff date provide the reduced form (or intent to treat) effect of relative age in grade on ADHD. To obtain the respective IV estimate of relative age we would need to divide the reduced form estimate by the compliance rate. We only observe the latter, however, on the grade level. In order to obtain the IV estimate, we would thus have to make assumptions on how the compliance rate varies across birth months. To avoid making these untestable assumptions we report the more transparent reduced form estimates. When comparing the results to the existing literature, we could scale our estimates with the overall compliance rate. As compliance is high in Germany this would only lead to small changes.

In principle, there are two margins along which we could compare children born in adjacent birth months around cutoff dates. First, we could compare children assigned to the same grade. Those born right after the cutoff are likely the oldest children in their grade, those born right before the cutoff the youngest. A disadvantage of this approach is that these children are essentially a year apart in age. They were in utero in different years and may have been subject to different general time shocks during their early childhood. Furthermore, if ADHD prevalence varies with age, the age trend may confound the relative age effect.

Second, we could compare children born in the same year just before and just after a specific cutoff date. These children are essentially of the same age and the issues with the first approach thus do 
not apply. However, these children are assigned to different grades. Therefore differences in ADHD prevalence may not only be due to relative age in grade but also depend on school exposure: Those born just before the cutoff are the youngest in their grade, while those born after the cutoff are the oldest. But those born before the cutoff have likely been in school for one additional year.

Our rich data allow us to look at both discussed margins - jumps in ADHD rates by age within grade as well as jumps in ADHD rates across adjacent birth months between grades. In a first step, we conduct a simple non-parametric analysis on how ADHD prevalence varies across birth cohorts (month and year of birth) and plot the fraction of children diagnosed with ADHD in a birth cohort (weighted by the number of children in the cohort) against the cohort's month and year of birth. To simplify the interpretation of these results as much as possible, we use only data from the 8 states that have not changed their cutoff dates (see Appendix Table 1) and conduct the analysis by data year. As all states without reforms in cutoff dates have the same cutoff (June 30), restricting the data to children in these states and looking at one specific year at a time results in a clear relationship between birth month and thus age and assigned grade level.

As a next step, we average the birth month differences over different birth cohorts in a regression analysis. We estimate the following equation

$$
A D H D_{i s t}=M o b_{i}+\epsilon_{i s t}
$$

by OLS, where $A D H D_{i s t}$ is the prevalence of ADHD diagnosis in birth cohort $i$, in state $s$, in data year $t$, $M o b_{i}$ represents month of birth dummies, and $\epsilon_{i s t}$ is an error term that captures all other influences on ADHD prevalence. All estimations are weighted by the number of children used to calculate the prevalence of ADHD diagnoses. Equation (1) is comparable to the reduced form estimations conducted in the earlier literature (e.g. Evans, Morrill, and Parente 2010; Dalsgaard et al. 2012). Similar to the earlier literature, we could include additional control variables in this estimation, such as state fixed effects, time fixed effects, and year of birth fixed effects. To the extent that month of birth is unlikely correlated with other influences on ADHD prevalence - in particular when considering differences across adjacent 
months of birth - adding these additional controls increases the precision but should not change the estimated coefficient. We use this framework to analyze differences across data years as well as differences across cohorts affected by different cutoff dates.

Finally, we are interested in explaining the origin of the jumps in ADHD prevalence across the cutoff dates. We construct aggregate measures of the jumps on the district level and analyze how they vary with district level observables. In particular, we use the difference in average ADHD prevalence between children born in the quarter before the cutoff date and children born in the quarter after the cutoff date to construct average jumps. We aggregate across quarters around the cutoff date (rather than single months) to increase the precision of these district level estimates which are in some cases based on relatively small populations. We further aggregate across different (assigned) grade levels to obtain one measure per district and data year. We then estimate the following equation

$$
\text { Jump }_{d t}=\alpha+\beta_{1} \text { Physicians }_{d t}+\beta_{2} \text { SES }_{d t}+\beta_{3} \text { Schools }_{d t}+\gamma X_{d t}+t_{t}+\eta_{d}+u_{d t}
$$

where Jump $d t$ represents the jump around the cutoff date averaged across different assigned grade levels in district $d$ and year $t$, Physicians, SES, and Schools are three vectors of district levels variables listed in Appendix Table 2 that represent measures of the supply of physicians in the district, SES in the district, and school environment in the district, respectively, and the vector $X$ captures additional control variables. $t$ captures data year fixed effects, $\eta_{d}$ captures district level fixed effects, and $u_{d t}$ denotes the error term.

Importantly, district characteristics such as the supply of physicians or the average size of school classes are not "randomly assigned" but themselves outcomes of other state or district level processes. If these processes also directly affected the incidence of ADHD misdiagnoses, the estimated coefficients in equation (2) would be biased and could not be interpreted causally. For example, there could be unobservable differences between states which facilitate the incidence of misdiagnoses and also impact the equilibrium density of physicians in the long-run. While it is difficult to think of concrete examples for such potential confounders, the inclusion of district level fixed effects absorbs any unobservable (and observable) differences between districts that do not change over time. This means we compare changes 
of characteristics within district over time and ask whether these changes are related to changes in the size of the cutoff jumps. A causal interpretation of these estimates requires assuming the absence of shocks to ADHD misdiagnoses that are also related to changes in the explanatory variables. Although it is hard to think of examples for such shocks, we refrain from interpreting the results causally in a strict sense. Instead, we take them as first suggestive evidence for possible relationships between ADHD misdiagnoses and outpatient care, the school system, or parental background.

\subsection{Limitations}

Although differences in underlying health may not exist before school entry, relative age in grade could in principle have an effect not only on the diagnosis of ADHD but also on its true prevalence, in which case the jump around the cutoff dates does not reflect misdiagnoses but differences in ADHD caused by the school system. However, Elder (2010) shows that parents' reports of ADHD symptoms among their children are not related to their children's relative age in grade, while teacher perceptions and ADHD diagnoses are affected. This suggests that at least children's behavior at home does not vary by assigned age in grade and makes it unlikely that being young for grade causes ADHD. ${ }^{6}$

Furthermore, as Evans et al (2010) note jumps in ADHD prevalence around the cutoff could potentially also indicate false negative diagnoses (underdiagnoses) among the older children in the grade rather than false positive diagnoses (overdiagnoses) among the younger children. Even though the nature of the disease as well as results from brain scans suggest that overdiagnoses are more likely and also more troublesome (Evans et al. 2010), we shed more light on the possibility of underdiagnoses by focusing on injuries.

It is known that children with ADHD are more likely to suffer accidents and injuries than healthy children (Nigg 2013). If the jumps were driven by false negative cases among the older children, we

\footnotetext{
${ }^{6}$ As Evans et al (2010) note, the relationship between relative age in grade and ADHD diagnosis and treatment is worrying even if it does not reflect misdiagnoses. School policies would then induce differences in ADHD prevalence and treatment for children that are on average identical except that one group is born before and the other after a specific legislative cutoff date. A relationship should thus lead to a reconsideration of school policies and diagnoses guidelines.
} 
should see a higher risk of injuries among the older children in the group of children without ADHD diagnosis. We therefore compare the fraction of injuries among children without ADHD diagnoses around the cutoff dates.

\section{Results}

In Table 1 we show ADHD rates over single years of age. In Figure 1 we plot ADHD rates over age disaggregated to the monthly level for all children in states with June 30 as school entry cutoff date. We focus on one data year, 2010, so that children at a certain age all belong to the same birth cohort, i.e. the age in months shown on the x-axis can be mapped to a unique month of birth. The dashed red line shows the school start assigned by the school entry cutoff. For the children who comply with the assigned entry date those to the left of the cutoff are not yet in school, while those one to twelve months to the right of the cutoff are in the first grade, those 13 to 24 months to the right are in the second grade, etc. The solid vertical lines indicate switches between assigned grade levels. The green line shows the overall age or cohort trend from a regression fitting a basis spline of $3^{\text {rd }}$ degree through the oldest cohorts in each assigned grade.

As already described in Table 1, ADHD rates increase until about age 10 and flatten thereafter. The variation in ADHD rates across months within assigned grades, however, suggests that this is not the whole story. In contrast to the overall positive age trend, there is a strongly negative age trend within grade and dramatic positive jumps between grades. The younger the children relative to their assigned classmates, the higher are their ADHD rates. And those born right before the cutoff (who are the youngest in their assigned grade) have up to one percentage point higher ADHD rates compared to those born right after the cutoff (who are the oldest in their assigned grade). Given a baseline rate of 3-5\%, a one percentage point difference is substantial. 
Since children born only one month apart are unlikely to be very different in their underlying health the dramatic jumps around the cutoff dates suggest that there is substantial misdiagnosis in ADHD. Notice that there are no cutoff jumps before the assigned school start, suggesting that the jumps are indeed induced by the school system and not reflecting preexisting differences in underlying health.

Figure 2 shows that the cutoff jumps in ADHD diagnosis rates translate into comparable jumps in prescription of ADHD medication of about 0.8 percentage points around the cutoff with a baseline of about $2.5 \%$ to $4 \%$. The younger children are thus not only at higher risk of ADHD diagnoses but also at higher risk of treatment with psychoactive drugs that have potential short- and long-term side effects on the children's physical and mental health.

Figure 3 shows the ADHD rates across age in months separately for boys and girls. The same pattern of negative age trends within grades and positive jumps around cutoffs between grades is visible for both genders, but the cutoff jumps are much more pronounced for boys who also have a higher average ADHD rate across all ages. It seems that boys are particularly strongly subject to misdiagnosis, a result that could also partly explain why their average ADHD rate is higher than for girls.

Our results thus far have focused on one single year of data so that ages could be mapped to individual birth dates. In Table 2 we show that the same pattern across birth months with jumps between June and July are observable across all four data years (pooled for the assigned grades 3 to 8) with a slight increase in the jump's magnitude over time from 0.9 percentage points in 2008 to 1.1 percentage points in 2011.

The absence of cutoff jumps before the assigned school entry date in Figure 2 suggested that the jumps are not due to preexisting health differences between cohorts born before and after the cutoff. However, from Figure 2 alone one cannot exclude that health differences between children born in June and July already exist before they enter school but are just not revealed, perhaps because children are not examined systematically. School entry medical examinations may then first reveal these differences. In Table 3 we compare the pattern across birth months, pooled across all data years, for states with the June 
30 cutoff (column 1) to states with cutoffs at July 31 (column 2), September 30 (column 3) and December 31 (column 4). None of the additional cutoff dates shows a significant difference in ADHD rates between June and July cohorts. However, a pronounced jump in ADHD rates across birth months is observable in all columns, with jumps occurring at different months, precisely matching the respective cutoff month. Figure B1 in the Appendix visualizes the estimated month coefficients. This result suggests that it is indeed the assigned cutoff date that leads to the ADHD jumps and not preexisting differences in children's health that just happen to coincide with a given cutoff.

Finally, one might wonder whether the jumps between grades and the negative age trend within grades could be driven by a general medical examination bias based on children's relative age which is not specific to ADHD. To shed light on possible differences in medical examination, Figures 4 and 5 display the fraction of children diagnosed with hay fever and diabetes across age. Analogously to Figures 1 and 2, we show results for the data year 2010 and states with June 30 as school entry cutoff. In contrast to the results on ADHD, there are no systematic jumps around the cutoff month for either of the two conditions. This finding indicates that the pattern observed for ADHD is not driven by relative-age dependent differences in general medical examination practices. ${ }^{7}$

Overall, these results suggest that the jumps around school entry cutoff dates are not mere statistical artifacts or driven by differences in latent health between cohorts but policy induced ADHD misdiagnoses. It is not clear whether these misdiagnoses represent overdiagnoses among younger students or underdiagnoses among older students in a given grade. Evans et al. (2010) provide evidence that cutoff jumps represent overdiagnosis and they also argue that the nature of the disease as well as results from brain scans suggest that overdiagnoses are more likely. We shed additional light on the possibility that cutoffs jumps represent underdiagnoses among older students by looking at injury rates. Children with untreated ADHD are more likely to suffer accidents and injuries (Nigg 2013) hence if cutoff jumps are

\footnotetext{
${ }^{7}$ Figure 4 shows a remarkable seasonal pattern for hay fever that persists across all ages: children born in winter months generally seem to have higher risks of hay fever compared to children born in summer months. These results reflect that season of birth can be significantly related to health.
} 
driven by underdiagnoses among older students, one should observe higher injury rates among these students.

Figure B.2 in the Appendix plots injury rates over age in states with a June 30 cutoff for children without ADHD diagnosis. Within most grades injury rates are indeed higher for older students but this pattern is driven by a general age effect. Injury rates among the oldest cohorts in one grade are similar to those of the youngest cohorts in the next higher grade. This absence of a relative age effect in injury rates among children without ADHD diagnosis is in line with the hypothesis that cutoff jumps represent overdiagnoses among younger students rather than underdiagnoses among older students.

A further way to assess whether cutoff jumps are driven by over- or underdiagnoses is to look at the relationship of cutoff jumps with overall ADHD levels. If the misdiagnoses around cutoff jumps proxy for a general tendency to over- (under-) diagnose then cutoff jumps should be positively (negatively) related to overall ADHD levels. We have already shown a positive relationship of cutoff jumps and overall ADHD levels in Figure 3 in the context of gender heterogeneity. In Figure 6 we show this relationship for different states as well as for existent studies in different countries.

The hollow circles in Figure 6 plot state averages of ADHD levels against the relative jump around cutoff dates. There is a strongly positive relationship: States with stronger jumps around cutoff dates (proxying for higher rates of misdiagnosis) have higher ADHD levels. The solid triangles compare the average for Germany (based on non-reform states) against the cutoff jumps and ADHD levels observed in Denmark (Dalsgaard et al. 2012), Canada (Morrow et al. 2012), the U.S. (Elder 2010; Evans, Morrill, and Parente 2010) and Iceland (Zoëga et al. 2012). There is a wide range of cutoff jumps, from 0 $\%$ in Denmark to about $50 \%$ in the U.S., but the association with ADHD levels is surprisingly linear and similar to the relationship across German states. This pattern is in line with the hypothesis that higher rates of overdiagnoses uncovered around age cutoffs are an indicator for a broader tendency to overdiagnose which could be a driving factor of high ADHD levels. 
A natural question to ask is therefore, what is driving the jumps in ADHD rates around the cutoff dates. Are they driven by the supply of doctors who might have financial incentives to diagnose and overprescribe, in particular in competitive market environments? Or is it a demand-side phenomenon, induced by parents who want their children to perform better in school or by teachers pushing for ADHD diagnosis and treatment to discipline their students?

To explore this question we analyze the relationship of cutoff jumps with a broad range of characteristics at the district level. There is considerable variation in cutoff jumps at the district level as illustrated by Figure B3 in the Appendix. We focus this analysis on the states without reforms of the cutoff dates as for these states we observe children assigned to grades 3 to 8 who are not directly affected by shifts in cutoff dates for all data years, which gives us a balanced panel of cohorts.

Table 4 contains descriptive statistics for the district characteristics that we analyze. The first group of variables shows the density of different types of physicians which commonly diagnose ADHD in Germany (all physicians are allowed to diagnose ADHD in Germany). As we can read from the first column, which shows means for all districts in non-reform states, the largest group are primary care physicians, followed by psychologists, and the smallest groups are pediatricians and psychiatrists. The next two groups of variables include characteristics of the school environment and of the parental background. About $7 \%$ of students are foreign while the average class size in primary school is $20.94 \%$ of employees have higher education, a variable that proxies for the educational attainment of the parent generation in a district, and log labor income is 7.9. The final group of district characteristics are control variables such as the overall physician density which we include in the regressions to absorb factors that determine the broader living environment without having a direct impact on ADHD diagnoses. The compliance rate, i.e. the share of students who enter school at the official school starting age, is high (86.1\% in this sample) compared to other countries (see section 1). In contrast to the other control variables, the compliance rate is measured at the state not the district level, which explains the low 
standard deviation of 5.9. We still include it as a control, as a low compliance rate would mechanically imply a smaller cutoff jump.

The second and third columns of Table 4 restrict the sample to districts with cutoff jumps below and above the median. Comparing the expert physician density in districts with below and above median cutoff jumps suggests that districts with larger cutoff jumps have a lower density of these expert physicians. This relationship would reject our hypothesis that more competitive physician markets lead to higher rates of misdiagnoses. However, the density of expert physicians might be correlated with third factors such as state legislation, urbanization or education levels in the population. These factors might also have direct effects on the rate of ADHD misdiagnoses and potentially bias the unconditional relationship of physician density and cutoff jumps. We therefore present regression results in Table 5 which control for a broad set of district characteristics. We also sequentially include state and district fixed effects to control for unobserved characteristics that do not change over time.

The first column of Table 5 shows regressions of the cutoff jump on district-level physician density, school characteristics, parental background, and control variables. The coefficients on all expert physician density variables are negative and in a similar range, though only the coefficient on psychologists is significantly different from zero. Apparently, a more competitive market environment does not lead to more misdiagnoses. If anything a higher expert physician density weakens the jumps around the cutoff dates. This pattern changes little when state and district fixed effects are added in columns (2) and (3).

The share of foreign students, on the other hand, has a persistently significant and positive effect on misdiagnoses. The coefficient is around 0.1 in the first two columns and increases slightly to 0.19 when district fixed effects are added in the column (3), suggesting that a 1 percentage point increase in the share of foreign students is associated with a 0.1 to 0.2 percentage point increase in the cutoff jump. Standard errors in columns (3) and (4) are large which is not surprising since the time-series variation of foreign 
student shares within states and districts is limited. Also note that we control for the share of foreigners in the overall population so this effect is not simply reflecting a general impact of migration.

In column (4) we restrict the sample to states which provide information on class sizes to include this variable of interest. Bigger classes correlate with higher rates of misdiagnoses. The effect of 0.22 is significant at the 10 percent level and suggests that an increase of the average class size by one student is associated with an increase in cutoff jumps by about a quarter of a percentage point. This is quite a large effect of about 24 percent given an average cutoff jump of 1 percentage point.

The coefficient of the share of employees with higher education is not significantly different from zero in the first two columns but it becomes positive and significant at the 5 percent level when we include district fixed effects. A similar pattern is observed for log labor income, which has a significant positive effect when state or district fixed effects are included. These estimates suggest that districts with improvements in parental education or income experience increases in misdiagnosis rates.

Table 6 shows regressions in the subsample that excludes states that have mandatory health exams by government physicians of all students in primary school (Mecklenburg-West Pomerania, Thuringia, Saxony, and Saxony-Anhalt). These health exams are systematically carried out in specific grades and therefore could add to the cutoff jumps in ADHD prevalence and treatment. Excluding these states affects some of the point estimates slightly but the overall pattern remains unchanged and becomes even stronger.

\section{Conclusion}

In this paper, we present strong and robust evidence of jumps in ADHD diagnosis and treatment around school entry cutoff dates in Germany based on the universe of outpatient claims for all children insured in the German social health insurance. Similar to other North American and European countries, children in Germany born in months right before the school entry cutoff dates have higher rates of ADHD diagnoses and a higher chance of receiving medical treatment for ADHD than children born in months right after the cutoff date. These jumps do not occur for children younger than 6 , the usual school starting 
age in Germany. Furthermore, the months between which the jumps occur vary with different cutoff dates across German states. It is therefore likely that the higher rates among the children born before the cutoff date result from the fact that these children belong to the youngest in their grade. Because of their lower age, these children are likely less attentive, more hyperactive and more impulsive than their older classmates, thus show higher ADHD symptoms and are therefore more likely to get diagnosed with ADHD.

Our results further suggest that these misdiagnoses of ADHD add to increases in the prevalence of diagnosed ADHD. We show that larger jumps in prevalence around school entry cutoff dates are strongly correlated with higher ADHD levels, both across German states as well as for the different countries that have been analyzed in the past. This relationship is surprisingly linear and homogenous across German states and internationally. These findings suggest that misdiagnoses, empirically detectable around age cutoffs, may be a driving force behind the high ADHD rates observed in many countries.

In the last part of the paper we analyze how changes in the ADHD jumps around cutoff dates vary with the supply of doctors, the school environment and SES. In this analysis we rely on district level variation over time, holding constant average observed and unobserved characteristics at the district level. Jumps in ADHD prevalence are negatively but hardly significantly related to the supply of doctors, but increase with worsening of teaching conditions, such as large classes, and with improvement of the general educational level of adults in the district. These findings could imply that in particular teachers and highly educated parents play a role for the additional ADHD diagnoses among the children who are young for their grade, while the supply of doctors hardly matters in the German setting. In order to interpret these results causally, however, we have to assume that there are no time-varying unobserved factors at the district level that drive jumps in ADHD prevalence and are related to the explanatory variables. Although it is hard to think of concrete examples for such factors, it remains a strong assumption and we therefore suggest interpreting the results as first evidence that the school environment 
and parental background may play a role for school entry age-related ADHD misdiagnoses. Future research should test the role of these factors based on truly exogenous variation.

Although we refrain from interpreting our results on the factors driving ADHD misdiagnoses causally, our study has several implications for future research and policy. In order to mitigate the effect of school entry age on ADHD diagnoses and reduce misdiagnoses, it is crucial to raise the awareness among doctors, parents and teachers that ADHD symptoms depend on a child's actual age while differences in age are large within today's classrooms. A further possibility to weaken the impact of age differences within classrooms on misdiagnoses is to only allow children to enter school if they are sufficiently mature, i.e. if they are sufficiently able to focus, sit still and control themselves to follow the school curriculum. This requires making school entry more flexible and deciding on a case-by-case basis whether a child should be enrolled in school or not.

Mitigating the effect of school entry age on ADHD diagnoses and thereby reducing ADHD misdiagnoses is important, as a wrongfully attributed diagnosis of ADHD can have dramatic consequences. An ADHD diagnosis may carry a stigma (Moses 2010). For a child who truly has ADHD this stigma may be outweighed by the benefits of treatment as well as the benefits for its classmates (Aizer 2008). However, a child who does not have ADHD cannot benefit from the treatment. Even worse, medical treatment for ADHD is known to have strong side effects, such as an increased risk of cardiovascular disease, effects on sleep and appetite (Gould et al. 2009; Cascade, Kalali, and Wigal 2010) as well as increases in emotional problems (Currie, Stabile, and Jones 2014). These side effects of wrongful ADHD diagnosis and treatment may have detrimental long-term impacts on human capital development and labor market outcomes. 


\section{References}

Aizer, Anna. 2008. "Peer Effects and Human Capital Accumulation: The Externalities of ADD." NBER Working Paper No 14354. National Bureau of Economic Research.

Bruchmüller, Katrin, and Silvia Schneider. 2012. "Fehldiagnose Aufmerksamkeitsdefizit- Und Hyperaktivitätssyndrom? Empirische Befunde Zur Frage Der Überdiagnostizierung,” Der Psychotherapeut, 57 (1): 77-89.

Cascade, Elisa, Amir H. Kalali, and Sharon B. Wigal. 2010. "Real-World Data on Attention Deficit Hyperactivity Disorder Medication Side Effects.” Psychiatry (Edgmont) 7 (4): 13-15.

Chorniy, A, and L Kitashima. 2014. "Sex, Drugs and ADHD: The Effects of ADHD Pharmacological Treatment on Children's Risky Behavior”. Working Paper.

Currie, Janet, and Hannes Schwandt. 2013. "Within-mother Analysis of Seasonal Patterns in Health at Birth,” Proceedings of the National Academy of Sciences (PNAS), 110 (30): 12265-70.

Currie, Janet, Mark Stabile, and Lauren Jones. 2014. "Do Stimulant Medications Improve Educational and Behavioral Outcomes for Children with ADHD?" Journal of Health Economics 37 (September): 58-69. doi:10.1016/j.jhealeco.2014.05.002.

Dalsgaard, Søren, Maria Knoth Humlum, Helena Skyt Nielsen, and Marianne Simonsen. 2012. "Relative Standards in ADHD Diagnoses: The Role of Specialist Behavior.” Economics Letters 117 (3): 663-65.

Dalsgaard, Søren, Helena Skyt Nielsen, and Marianne Simonsen. 2014. "Consequences of ADHD Medication Use for Children's Outcomes." Journal of Health Economics 37 (September): 137-51. doi:10.1016/j.jhealeco.2014.05.005.

Elder, Todd E. 2010. “The Importance of Relative Standards in ADHD Diagnoses: Evidence Based on Exact Birth Dates.” Journal of Health Economics 29 (5): 641-56. doi:10.1016/j.jhealeco.2010.06.003.

Evans, William N., Melinda S. Morrill, and Stephen T. Parente. 2010. "Measuring Inappropriate Medical Diagnosis and Treatment in Survey Data: The Case of ADHD Among School-age Children.” Journal of Health Economics 29 (5): 657-73. doi:10.1016/j.jhealeco.2010.07.005.

Faraone, Stephen V., Roy H. Perlis, Alysa E. Doyle, Jordan W. Smoller, Jennifer J. Goralnick, Meredith A. Holmgren, and Pamela Sklar. 2005. "Molecular Genetics of Attention-Deficit/Hyperactivity Disorder.” Biological Psychiatry 57 (11): 1313-23. doi:10.1016/j.biopsych.2004.11.024.

Federal Statistical Office. 2014. "Allgemeinbildende Schulen - Fachserie 11, Reihe 1."

Furman, Lydia. 2005. "What Is Attention-Deficit Hyperactivity Disorder (ADHD)?,” Journal of Child Neurology, 20 (12): 994-1002. 
German Association for Child and Youth Psychiatry et al. 2007. In Leitlinien Zur Diagnostik Und

Therapie von Psychischen Störungen Im Säuglings-, Kindes- Und Jugendalter, 3rd ed., 239 - 254. Berlin: Deutscher Ärzte Verlag.

Gould, Madelyn S., B. Timothy Walsh, Jimmie Lou Munfakh, Marjorie Kleinman, Naihua Duan, Mark Olfson, Laurence Greenhill, and Thomas Cooper. 2009. "Sudden Death and Use of Stimulant Medications in Youths." American Journal of Psychiatry 166 (9): 992-1001. doi:10.1176/appi.ajp.2009.09040472.

Grobe, T.G., E.M. Bitzer, and F.W. Schwartz. 2013. "Barmer GEK Arztreport 2013”. Schriftenreihe zur Gesundheitsanalyse, Band 18.

Halldner, Linda, Annika Tillander, Cecilia Lundholm, Marcus Boman, Niklas Långström, Henrik Larsson, and Paul Lichtenstein. 2014. "Relative Immaturity and ADHD: Findings from Nationwide Registers, Parent- and Self-reports.” Journal of Child Psychology and Psychiatry 55 (8): 897-904. doi:10.1111/jcpp.12229.

Hering, Ramona, Mandy Schulz, Amelie Wuppermann, and Jörg Bätzing-Feigenbaum. 2014. "Die Aufmerksamkeitsdefizit-/Hyperaktivitätsstörung (ADHS) Bei Kindern Und Jugendlichen in Der Ambulanten Versorgung in Deutschland - Teil 1 - Entwicklung Der Diagnose- Und Medikationsprävalenzen von ADHS Zwischen 2008 Und 2011 Im Regionalen Vergleich”. Versorgungsatlas.

Krabbe, E. E., E. D. Thoutenhoofd, M. Conradi, S. J. Pijl, and L. Batstra. 2014. "Birth Month as Predictor of ADHD Medication Use in Dutch School Classes." European Journal of Special Needs Education 29 (4): 571-78. doi:10.1080/08856257.2014.943564.

Lohmar, Brigitte, and Thomas Eckhardt. 2013. Bonn: Secretariat of the Standing Conference of the Ministers of Education and Cultural Affairs of the Länder in the Federal Republic of Germany. http://www.kmk.org/fileadmin/doc/Dokumentation/Bildungswesen_en_pdfs/dossier_en_ebook.pdf.

Morrow, Richard L., E. Jane Garland, James M. Wright, Malcolm Maclure, Suzanne Taylor, and Colin R. Dormuth. 2012. "Influence of Relative Age on Diagnosis and Treatment of Attentiondeficit/hyperactivity Disorder in Children.” Canadian Medical Association Journal 184 (7): 75562. doi:10.1503/cmaj.111619.

Moses, Tally. 2010. "Being Treated Differently: Stigma Experiences with Family, Peers, and School Staff Among Adolescents with Mental Health Disorders.” Social Science \& Medicine 70 (7): 985-93. doi:10.1016/j.socscimed.2009.12.022.

Nigg, Joel T. 2013. “Attention-deficit/hyperactivity Disorder and Adverse Health Outcomes." Clinical Psychology Review 33 (2): 215-28. doi:10.1016/j.cpr.2012.11.005. 
Pottegård, Anton, Jesper Hallas, null Hernández-Díaz, and Helga Zoëga. 2014. "Children’s Relative Age in Class and Use of Medication for ADHD: a Danish Nationwide Study." Journal of Child Psychology and Psychiatry, and Allied Disciplines 55 (11): 1244-50. doi:10.1111/jcpp.12243.

Schwandt, Hannes. 2015. "The Lasting Legacy of Seasonal Influenza: In-utero Exposure and Human Capital Development." mimeo.

Tarver, J., D. Daley, and K. Sayal. 2014. “Attention-deficit Hyperactivity Disorder (ADHD): An Updated Review of the Essential Facts." Child: Care, Health and Development 40 (6): 762-74. doi:10.1111/cch.12139.

Zoëga, Helga, Unnur A. Valdimarsdóttir, and Sonia Hernández-Díaz. 2012. “Age, Academic Performance, and Stimulant Prescribing for ADHD: a Nationwide Cohort Study.” Pediatrics 130 (6): 1012-18. 


\section{Figures and Tables}

Figure 1: ADHD prevalence across age, in states with June 30 as school entry cutoff date.

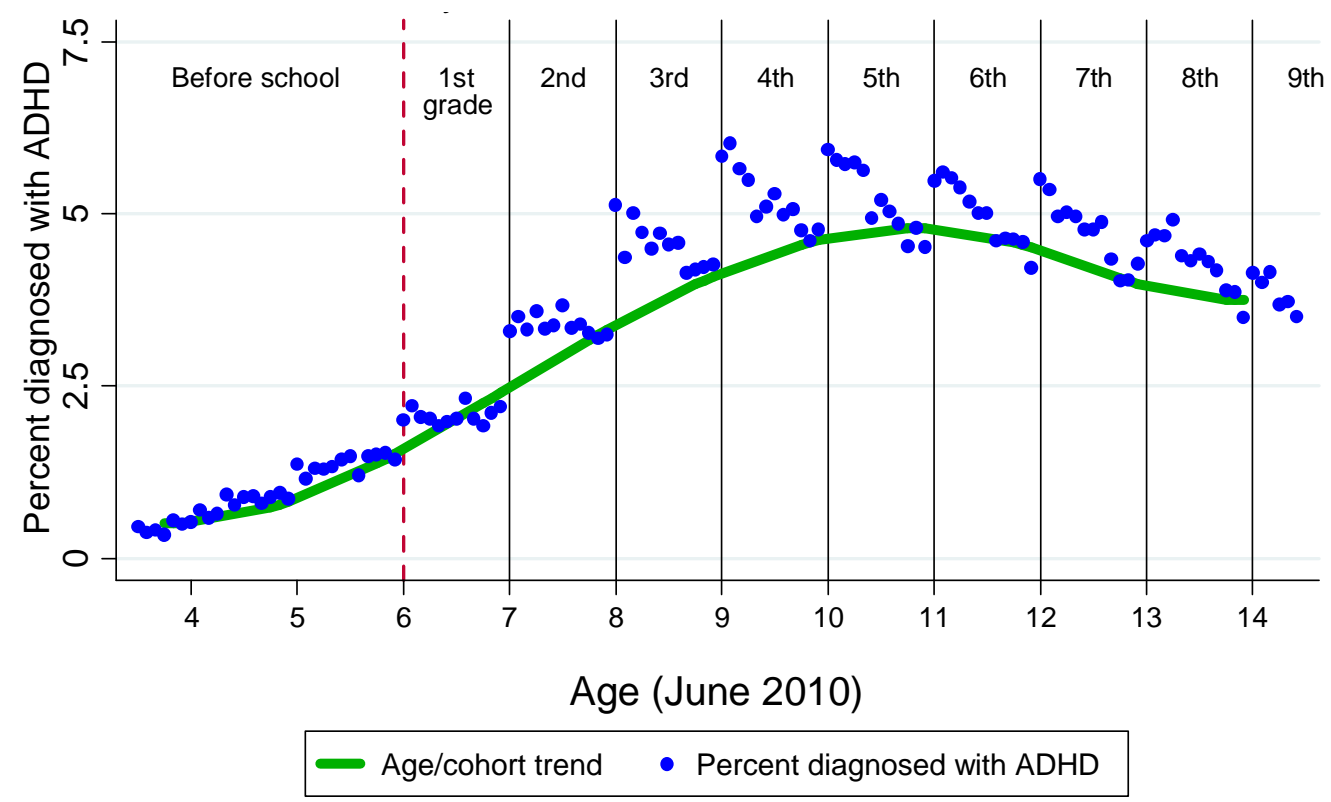

Notes: This figure shows the percent of school children diagnosed with ADHD in 2010 by children's age, measured in months as of June 2010. The sample includes all states with June 30 as school entry cutoffs and without reforms in the cutoff dates. $\mathrm{N}=1,685,730$. Average ADHD prevalence is 3.5\%. The dashed line indicates the assigned school start (i.e. those who are of age 6 or above in June 2010 are supposed to enter school). The solid lines show the respective assigned cutoffs between grades at higher ages. 
Figure 2: ADHD medication across age, in states with June 30 as school entry cutoff date.

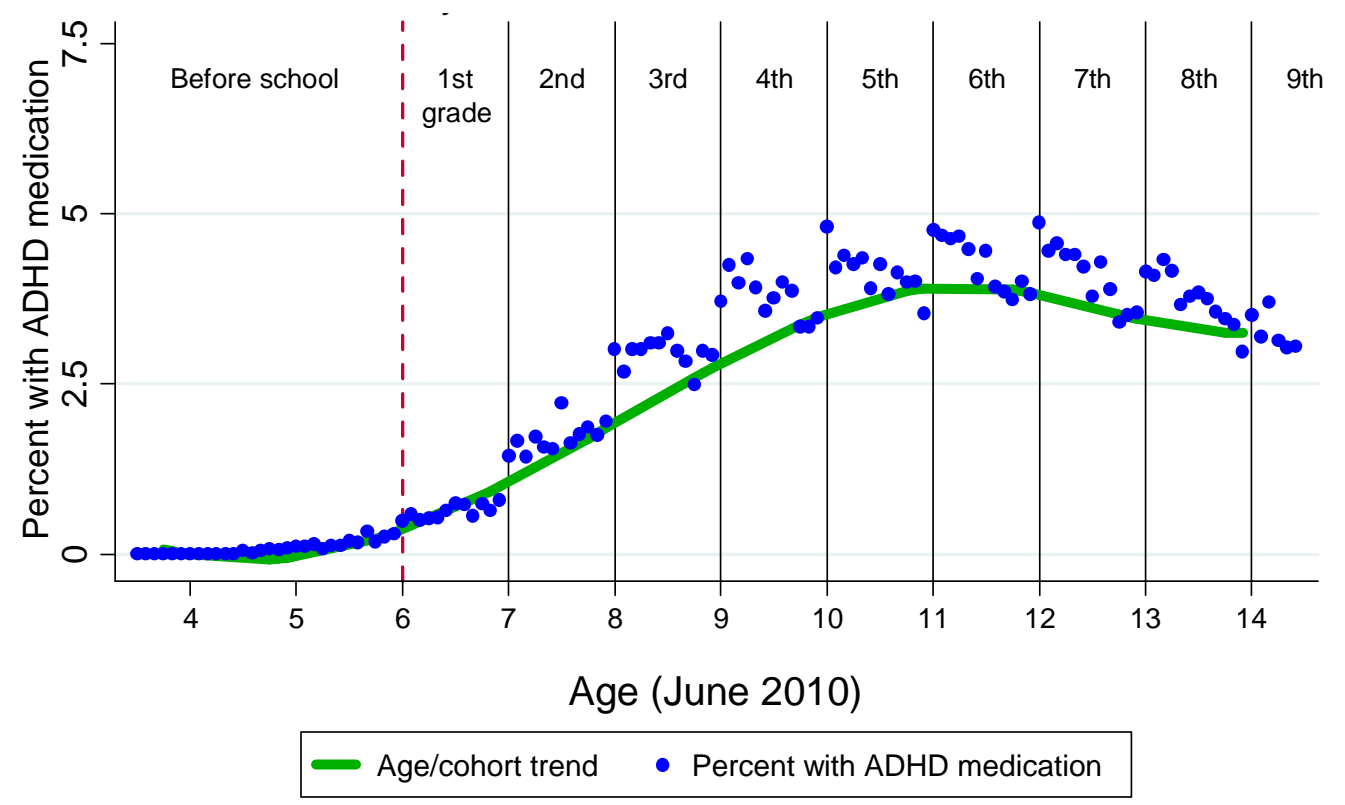

Notes: This figure shows the percent of school children who receive Methylphenidate or Atomoxetin in 2010 by children's age, measured in months as of June 2010. The sample includes all states with June 30 as school entry cutoffs and without reforms in the cutoff dates. $\mathrm{N}=1,685,730$. Average ADHD treatment is $2.45 \%$. The dashed line indicates the assigned school start (i.e. those who are of age 6 or above in June 2010 are supposed to enter school). The solid lines show the respective assigned cutoffs between grades at higher ages. 
Figure 3: ADHD prevalence across age, by gender (June 30 cutoff date).

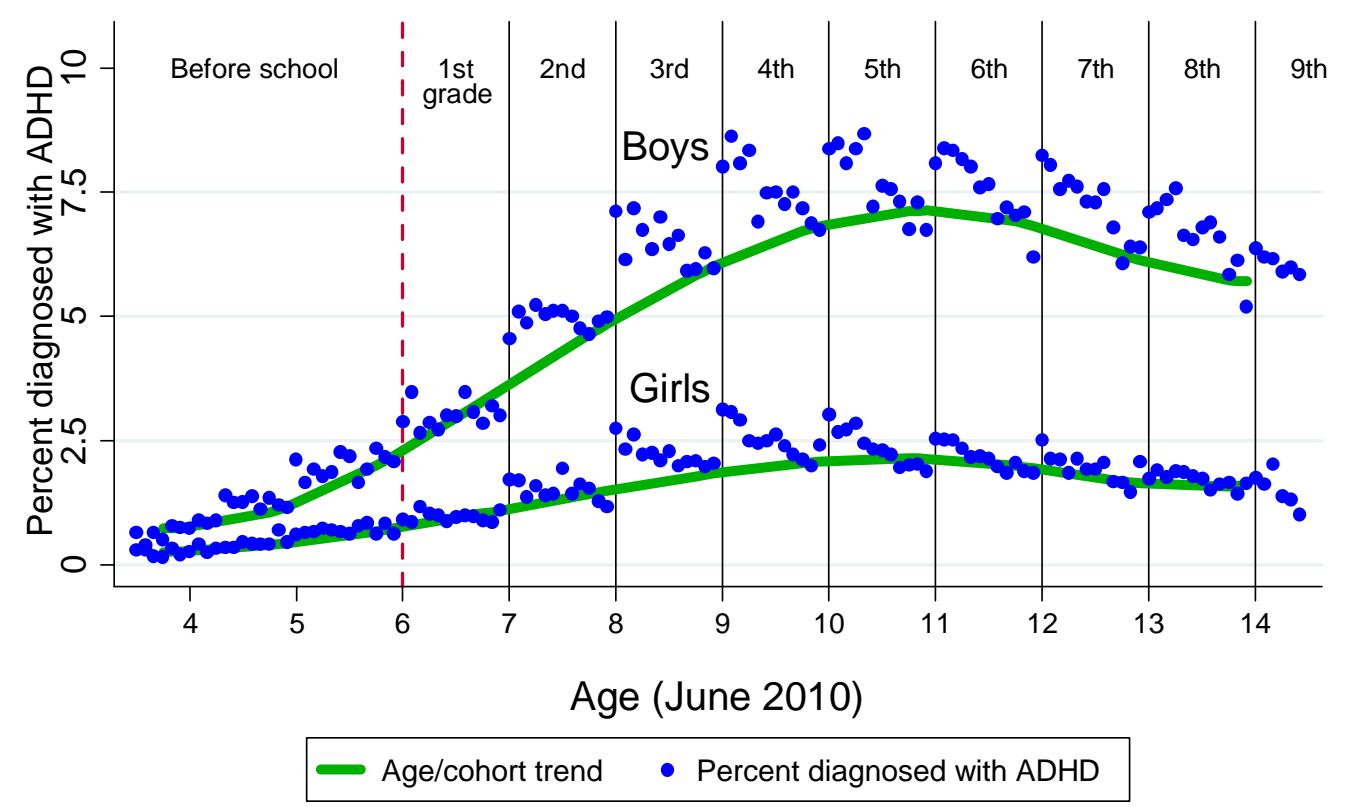

Notes: This figure shows the percent of boys and girls diagnosed with ADHD in 2010 by children's age, measured in months as of June 2010. The sample includes all states with June 30 as school entry cutoffs and without reforms in the cutoff dates. $\mathrm{N}$ (boys) $=799,576 . \mathrm{N}$ (girls) $=768,926$. Average ADHD prevalence is $5.22 \%$ for boys and $1.58 \%$ for girls. The dashed line indicates the assigned school start (i.e. those who are of age 6 or above in June 2010 are supposed to enter school). The solid lines show the respective assigned cutoffs between grades at higher ages. 
Figure 4: Hay fever prevalence across age, in states with June 30 as school entry cutoff date.

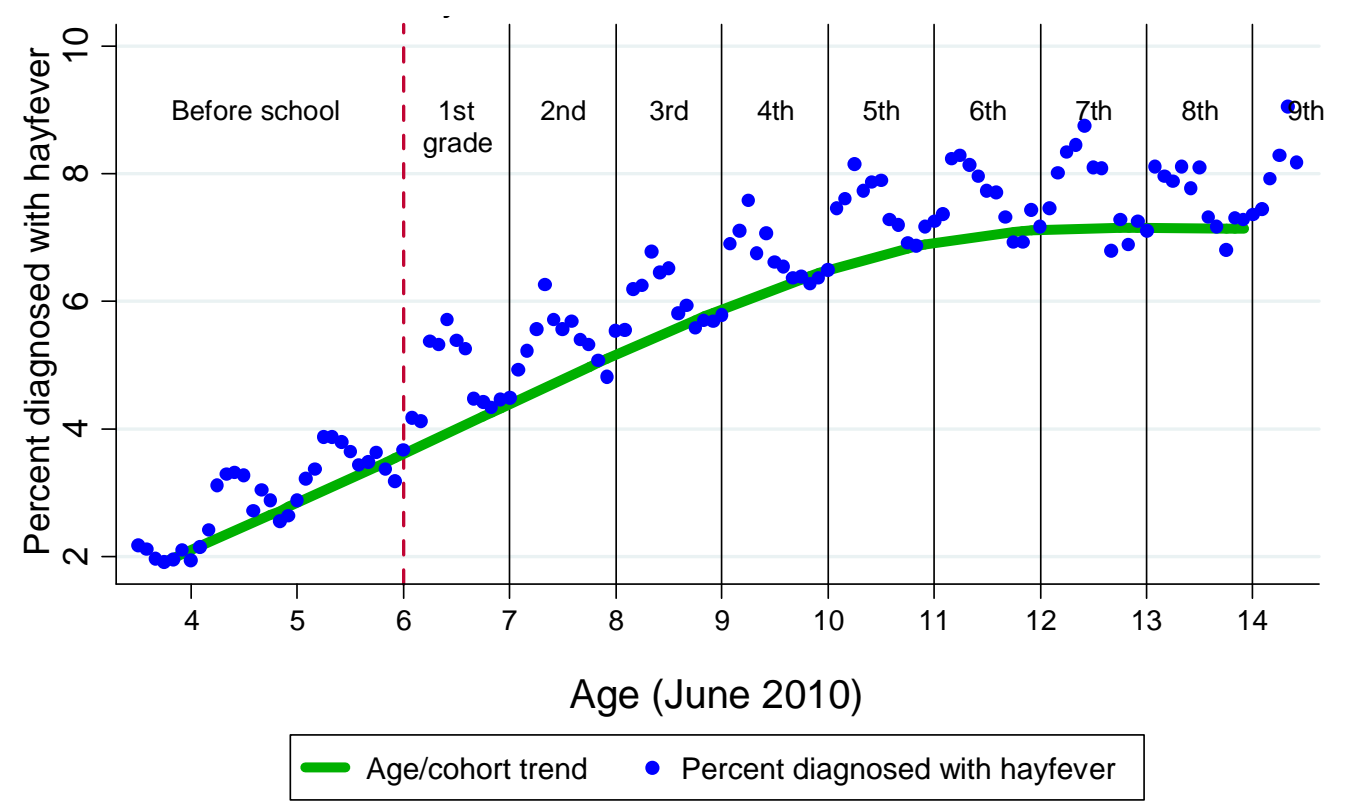

Notes: This figure shows the percent of school children diagnosed with Hay fever in 2010 by children's age, measured in months as of June 2010. The sample includes all states with June 30 as school entry cutoffs and without reforms in the cutoff dates. $\mathrm{N}=1,685,730$. Average prevalence is $5.81 \%$. The dashed line indicates the assigned school start (i.e. those who are of age 6 or above in June 2010 are supposed to enter school). The solid lines show the respective assigned cutoffs between grades at higher ages. 
Figure 5: Diabetes prevalence across age, in states with June 30 as school entry cutoff date.

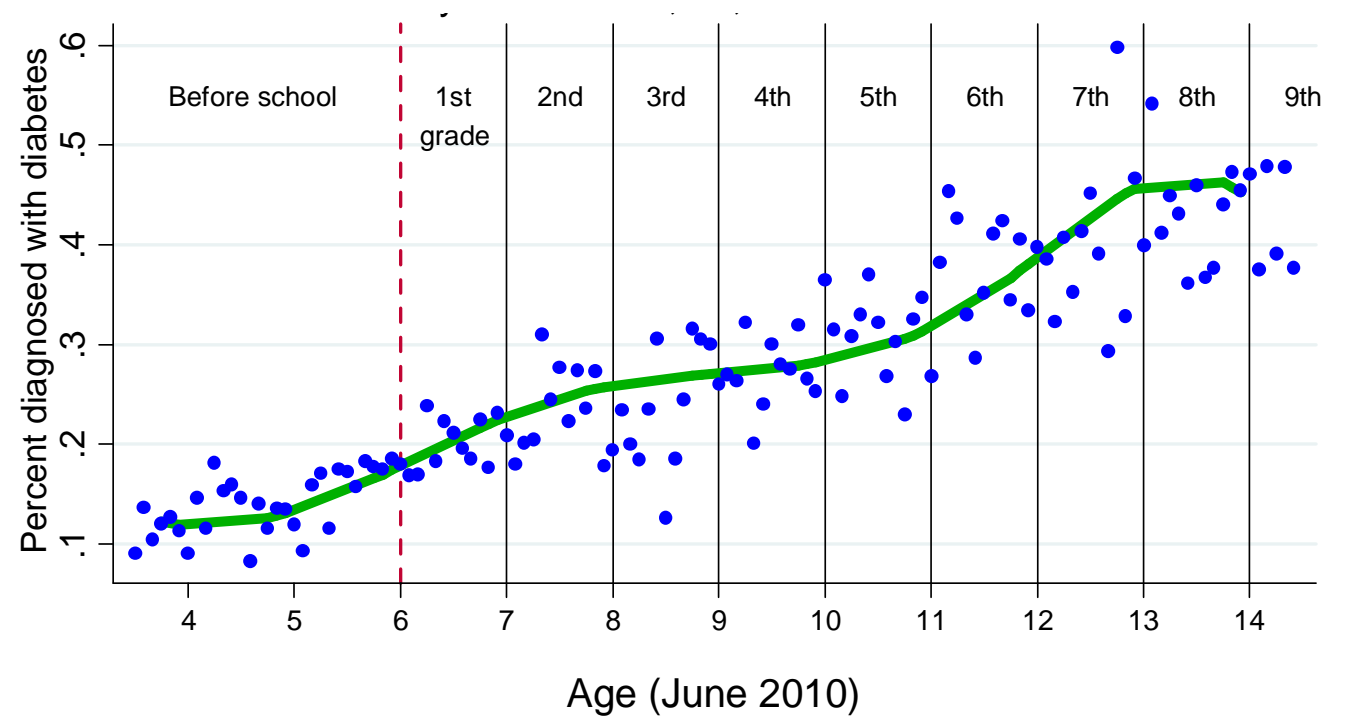

Age/cohort trend

- Percent diagnosed with diabetes

Notes: This figure shows the percent of school children diagnosed with diabetes in 2010 by children's age, measured in months as of June 2010. The sample includes all states with June 30 as school entry cutoffs and without reforms in the cutoff dates. $\mathrm{N}=1,685,730$. Average prevalence is $\%$. The dashed line indicates the assigned school start (i.e. those who are of age 6 or above in June 2010 are supposed to enter school). The solid lines show the respective assigned cutoffs between grades at higher ages. 
Figure 6: Jumps in ADHD rates around cutoff dates and ADHD levels, state and country averages.

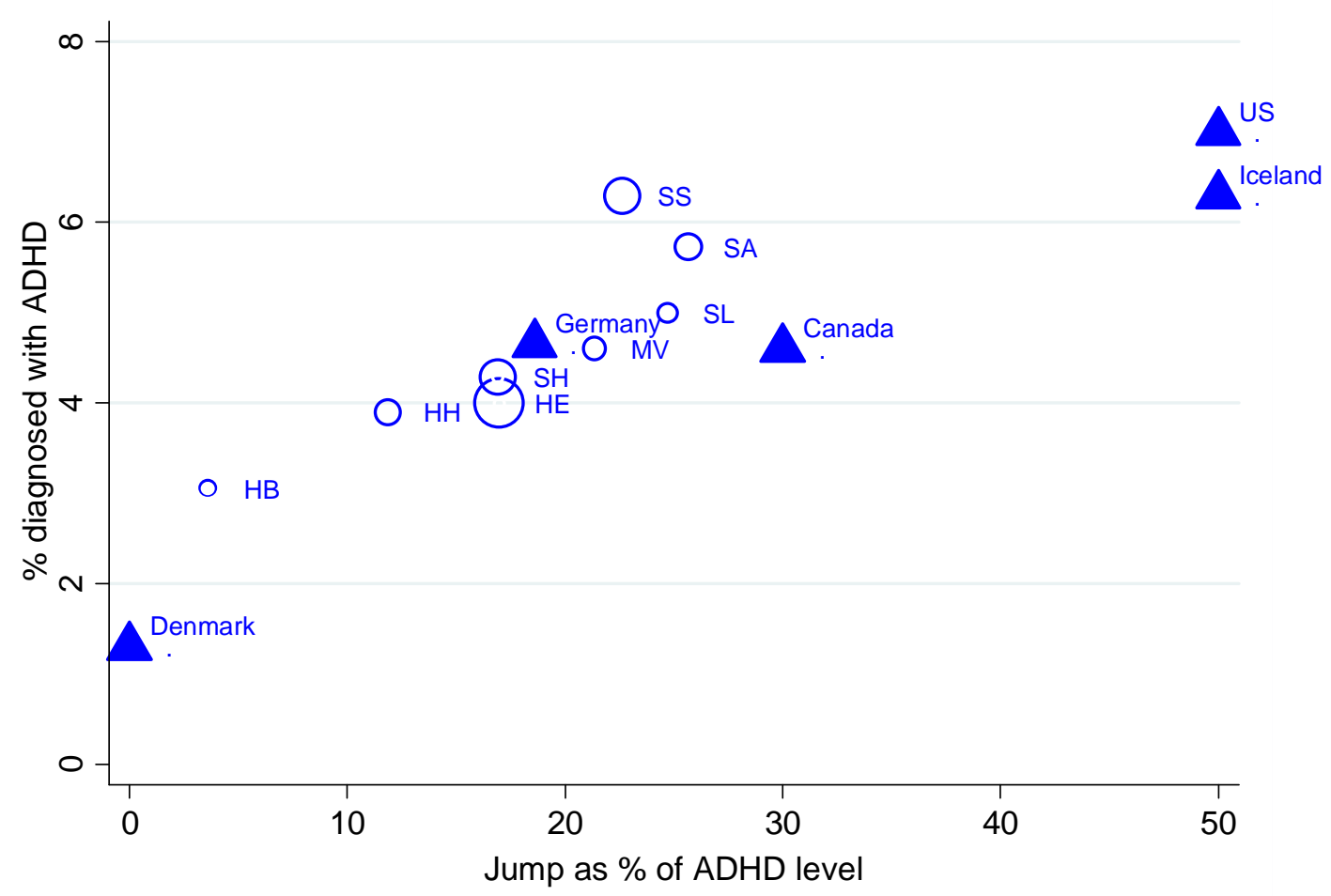

Notes: Circles show average rates for German states without reforms of the cutoff date (HB-Bremen, HE-Hesse, HHHamburg, MV-Mecklenburg-West Pomerania, SA-Saxony-Anhalt, SL-Saarland, SS-Saxony), pooled across 20082011 , for the grades 3 to 8 . The triangles for Germany presents the weighted average of these state observations. The averages for Denmark, Canada, the U.S., and Iceland are derived from Dalsgaard et al. 2012, Morrow et al. 2012, Elder 2010 and Evans at al. 2010, and Zoëga et al. 2012, respectively. The rates for Iceland refer to ADHD medication rates (rather than diagnosis rates). 


\begin{tabular}{|c|c|c|c|c|c|c|c|c|c|c|c|c|}
\hline & \multirow[b]{2}{*}{$\begin{array}{c}\text { All States } \\
\text { (1) }\end{array}$} & \multirow[b]{2}{*}{$\begin{array}{l}\text { States wlo } \\
\text { cutoff } \\
\text { reforms } \\
(2)\end{array}$} & \multicolumn{10}{|c|}{ By assigned grade level (States wlo reform) } \\
\hline & & & $\begin{array}{l}-2 \\
(3) \\
\end{array}$ & $\begin{array}{l}-1 \\
(4)\end{array}$ & $\begin{array}{l}1^{\text {st }} \\
(5)\end{array}$ & $\begin{array}{l}2^{\text {nd }} \\
(6)\end{array}$ & $\begin{array}{l}3^{\mathrm{rd}} \\
(7)\end{array}$ & $\begin{array}{l}4^{\text {th }} \\
(8)\end{array}$ & $\begin{array}{l}5^{\text {th }} \\
(9) \\
\end{array}$ & $\begin{array}{l}6^{\text {th }} \\
(10) \\
\end{array}$ & $\begin{array}{l}7^{\text {th }} \\
(11) \\
\end{array}$ & $\begin{array}{l}8^{\text {th }} \\
(12) \\
\end{array}$ \\
\hline Age (June) & $\begin{array}{c}9.085 \\
(3.177)\end{array}$ & $\begin{array}{c}8.959 \\
(3.174)\end{array}$ & $\begin{array}{c}4.514 \\
(0.293)\end{array}$ & $\begin{array}{c}5.515 \\
(0.293)\end{array}$ & $\begin{array}{c}6.516 \\
(0.292)\end{array}$ & $\begin{array}{c}7.517 \\
(0.292)\end{array}$ & $\begin{array}{c}8.517 \\
(0.292)\end{array}$ & $\begin{array}{c}9.517 \\
(0.292)\end{array}$ & $\begin{array}{c}10.52 \\
(0.292)\end{array}$ & $\begin{array}{c}11.52 \\
(0.292)\end{array}$ & $\begin{array}{c}12.52 \\
(0.292)\end{array}$ & $\begin{array}{c}13.52 \\
(0.292)\end{array}$ \\
\hline $\begin{array}{c}\text { ADHD (\%) } \\
\text { Diagnosis }\end{array}$ & $\begin{array}{c}3.840 \\
(2.064)\end{array}$ & $\begin{array}{c}3.381 \\
(1.874)\end{array}$ & $\begin{array}{c}0.736 \\
(0.360)\end{array}$ & $\begin{array}{c}1.344 \\
(0.589)\end{array}$ & $\begin{array}{c}2.010 \\
(0.724)\end{array}$ & $\begin{array}{c}3.303 \\
(0.900)\end{array}$ & $\begin{array}{c}4.416 \\
(1.161)\end{array}$ & $\begin{array}{c}5.005 \\
(1.310)\end{array}$ & $\begin{array}{c}4.985 \\
(1.298)\end{array}$ & $\begin{array}{c}4.826 \\
(1.197)\end{array}$ & $\begin{array}{c}4.557 \\
(1.078)\end{array}$ & $\begin{array}{c}4.104 \\
(0.953)\end{array}$ \\
\hline $\begin{array}{r}\text { Medical } \\
\text { Treatment }\end{array}$ & $\begin{array}{c}2.745 \\
(1.922)\end{array}$ & $\begin{array}{c}2.374 \\
(1.740)\end{array}$ & $\begin{array}{c}0.0567 \\
(0.0783)\end{array}$ & $\begin{array}{c}0.199 \\
(0.134)\end{array}$ & $\begin{array}{c}0.668 \\
(0.288)\end{array}$ & $\begin{array}{c}1.733 \\
(0.528)\end{array}$ & $\begin{array}{c}2.882 \\
(0.757)\end{array}$ & $\begin{array}{c}3.730 \\
(0.930)\end{array}$ & $\begin{array}{c}3.991 \\
(0.977)\end{array}$ & $\begin{array}{c}4.044 \\
(0.930)\end{array}$ & $\begin{array}{c}3.861 \\
(0.904)\end{array}$ & $\begin{array}{c}3.525 \\
(0.821)\end{array}$ \\
\hline $\begin{array}{l}\text { Hayfever } \\
(\%)\end{array}$ & $\begin{array}{c}5.829 \\
(2.108)\end{array}$ & $\begin{array}{c}5.858 \\
(2.391)\end{array}$ & $\begin{array}{c}2.754 \\
(0.915)\end{array}$ & $\begin{array}{c}3.760 \\
(1.189)\end{array}$ & $\begin{array}{c}4.514 \\
(1.296)\end{array}$ & $\begin{array}{c}5.370 \\
(1.470)\end{array}$ & $\begin{array}{c}6.022 \\
(1.543)\end{array}$ & $\begin{array}{c}6.694 \\
(1.582)\end{array}$ & $\begin{array}{c}7.267 \\
(1.674)\end{array}$ & $\begin{array}{c}7.805 \\
(1.600)\end{array}$ & $\begin{array}{c}7.735 \\
(1.620)\end{array}$ & $\begin{array}{c}7.817 \\
(1.556)\end{array}$ \\
\hline $\begin{array}{l}\text { Diabetes } \\
(\%)\end{array}$ & $\begin{array}{c}0.294 \\
(0.139)\end{array}$ & $\begin{array}{c}0.279 \\
(0.177)\end{array}$ & $\begin{array}{c}0.158 \\
(0.118)\end{array}$ & $\begin{array}{c}0.189 \\
(0.139)\end{array}$ & $\begin{array}{c}0.207 \\
(0.142)\end{array}$ & $\begin{array}{c}0.231 \\
(0.149)\end{array}$ & $\begin{array}{c}0.254 \\
(0.155)\end{array}$ & $\begin{array}{c}0.280 \\
(0.155)\end{array}$ & $\begin{array}{c}0.314 \\
(0.154)\end{array}$ & $\begin{array}{c}0.354 \\
(0.158)\end{array}$ & $\begin{array}{c}0.396 \\
(0.174)\end{array}$ & $\begin{array}{c}0.421 \\
(0.170)\end{array}$ \\
\hline N kids & $29,015,143$ & $6,820,814$ & 633,025 & 629,615 & 621,939 & 614,738 & 617,244 & 623,508 & 624,379 & 624,755 & 612,613 & 598,563 \\
\hline N states & 16 & 8 & 8 & 8 & 8 & 8 & 8 & 8 & 8 & 8 & 8 & 8 \\
\hline $\mathbf{N}$ districts & 412 & 95 & 95 & 95 & 95 & 95 & 95 & 95 & 95 & 95 & 95 & 95 \\
\hline $\mathbf{N}$ years & 4 & 4 & 4 & 4 & 4 & 4 & 4 & 4 & 4 & 4 & 4 & 4 \\
\hline
\end{tabular}

Notes: Means and SD in parentheses. All children aged 4-14 in years 2008-2011 who have public health insurance and had at least 1 doctor visit or prescription

filled in respective year. Assigned grade levels refer to grades that kids should be in at the end of the data year according to their birth date and state of residence. -2 refers to the cohort that are assigned to enter school 2 years later. Information for assigned grades -3 and 9 not shown, as only half of the cohorts available for these assigned grade levels. 
Table 2: ADHD by month of birth - assigned grades 3 to 8 - Cutoff June 30

\begin{tabular}{|c|c|c|c|c|c|}
\hline & $\begin{array}{c}2008 \\
(1)\end{array}$ & $\begin{array}{c}2009 \\
(2) \\
\end{array}$ & $\begin{array}{c}2010 \\
(3) \\
\end{array}$ & $\begin{array}{c}2011 \\
(4) \\
\end{array}$ & $\begin{array}{c}\text { All years } \\
(5)\end{array}$ \\
\hline \multicolumn{6}{|c|}{ Month of Birth - Ref Jan } \\
\hline \multirow[t]{2}{*}{ Feb } & 0.002 & 0.002 & 0.001 & 0.001 & 0.002 \\
\hline & $(0.002)$ & $(0.002)$ & $(0.002)$ & $(0.002)$ & $(0.001)$ \\
\hline \multirow[t]{2}{*}{ Mar } & $0.004 *$ & 0.003 & $0.004 *$ & 0.003 & $0.004 * * *$ \\
\hline & $(0.002)$ & $(0.002)$ & $(0.002)$ & $(0.002)$ & $(0.001)$ \\
\hline \multirow[t]{2}{*}{ Apr } & $0.004 *$ & $0.004^{*}$ & $0.004 *$ & 0.004 & $0.004 * * *$ \\
\hline & $(0.002)$ & $(0.002)$ & $(0.002)$ & $(0.002)$ & $(0.001)$ \\
\hline \multirow[t]{2}{*}{ May } & $0.005 * *$ & $0.005 * *$ & $0.005^{* *}$ & $0.004 *$ & $0.005 * * *$ \\
\hline & $(0.002)$ & $(0.002)$ & $(0.002)$ & $(0.002)$ & $(0.001)$ \\
\hline \multirow[t]{2}{*}{ Jun } & $0.005^{* *}$ & $0.005 * *$ & $0.006 * *$ & $0.006^{* *}$ & $0.005 * * *$ \\
\hline & $(0.002)$ & $(0.002)$ & $(0.002)$ & $(0.002)$ & $(0.001)$ \\
\hline \multirow[t]{2}{*}{ Jul } & -0.004 & $-0.005^{* *}$ & $-0.005 * *$ & $-0.005^{* *}$ & $-0.005^{* * *}$ \\
\hline & $(0.002)$ & $(0.002)$ & $(0.002)$ & $(0.002)$ & $(0.001)$ \\
\hline \multirow[t]{2}{*}{ Aug } & -0.003 & -0.003 & $-0.004 *$ & $-0.004 *$ & $-0.004 * * *$ \\
\hline & $(0.002)$ & $(0.002)$ & $(0.002)$ & $(0.002)$ & $(0.001)$ \\
\hline \multirow[t]{2}{*}{ Sep } & $-0.004 *$ & $-0.005^{*}$ & $-0.005^{*}$ & $-0.005 * *$ & $-0.004 * * *$ \\
\hline & $(0.002)$ & $(0.002)$ & $(0.002)$ & $(0.002)$ & $(0.001)$ \\
\hline \multirow[t]{2}{*}{ Oct } & -0.002 & -0.002 & -0.003 & -0.002 & $-0.002 *$ \\
\hline & $(0.002)$ & $(0.002)$ & $(0.002)$ & $(0.002)$ & $(0.001)$ \\
\hline \multirow[t]{2}{*}{ Nov } & 0.001 & -0.000 & -0.001 & -0.001 & -0.000 \\
\hline & $(0.002)$ & $(0.002)$ & $(0.002)$ & $(0.002)$ & $(0.001)$ \\
\hline \multirow[t]{2}{*}{ Dec } & 0.002 & 0.000 & 0.001 & 0.001 & 0.001 \\
\hline & $(0.002)$ & $(0.002)$ & $(0.002)$ & $(0.002)$ & $(0.001)$ \\
\hline N kids & 929,284 & 946,150 & 917,382 & 908,246 & $3,701,062$ \\
\hline ADHD prev. (\%) & 4.29 & 4.5 & 4.79 & 4.85 & 4.61 \\
\hline p-value $($ Jun=Jul) & .000147 & $<0.0001$ & $<0.0001$ & $<0.0001$ & $<0.0001$ \\
\hline
\end{tabular}

Notes: Coefficients after OLS estimation. Including only children in states without reforms of cutoff dates. Last row shows p-values for tests of hypothesis that June and July coefficient are equal. 
Table 3: Different cutoff dates - grades 3 to 8

\begin{tabular}{|c|c|c|c|c|}
\hline & $\begin{array}{c}\text { June } 30 \\
\text { (1) }\end{array}$ & $\begin{array}{c}\text { July } 31 \\
\text { (2) }\end{array}$ & $\begin{array}{c}\text { Sept } 30 \\
\text { (3) }\end{array}$ & $\begin{array}{l}\text { Dec 31 } \\
\text { (4) }\end{array}$ \\
\hline \multicolumn{5}{|c|}{ Month of Birth - Ref Jan } \\
\hline $\mathrm{Feb}$ & $\begin{array}{c}0.002 \\
(0.001)\end{array}$ & $\begin{array}{c}0.001 \\
(0.004)\end{array}$ & $\begin{array}{c}0.003 \\
(0.004)\end{array}$ & $\begin{array}{c}0.005 \\
(0.003)\end{array}$ \\
\hline Mar & $\begin{array}{c}0.004 * * * \\
(0.001)\end{array}$ & $\begin{array}{c}0.003 \\
(0.004)\end{array}$ & $\begin{array}{c}0.006 \\
(0.004)\end{array}$ & $\begin{array}{c}0.003 \\
(0.003)\end{array}$ \\
\hline Apr & $\begin{array}{c}0.004 * * * \\
(0.001)\end{array}$ & $\begin{array}{l}0.006^{*} \\
(0.004)\end{array}$ & $\begin{array}{c}0.006 \\
(0.004)\end{array}$ & $\begin{array}{l}-0.001 \\
(0.003)\end{array}$ \\
\hline May & $\begin{array}{c}0.005 * * * \\
(0.001)\end{array}$ & $\begin{array}{c}0.007 * * \\
(0.004)\end{array}$ & $\begin{array}{c}0.009^{* *} \\
(0.004)\end{array}$ & $\begin{array}{c}0.004 \\
(0.003)\end{array}$ \\
\hline Jun & $\begin{array}{c}0.005^{* * * *} \\
(0.001)\end{array}$ & $\begin{array}{c}0.005 \\
(0.004)\end{array}$ & $\begin{array}{l}0.010^{* *} \\
(0.004)\end{array}$ & $\begin{array}{c}0.009 * * * \\
(0.003)\end{array}$ \\
\hline Jul & $\begin{array}{c}-0.005^{* * * *} \\
(0.001)\end{array}$ & $\begin{array}{l}0.007 * \\
(0.004)\end{array}$ & $\begin{array}{l}0.007^{*} \\
(0.004)\end{array}$ & $\begin{array}{c}0.009 * * * \\
(0.003)\end{array}$ \\
\hline Aug & $\begin{array}{c}-0.004 * * * \\
(0.001)\end{array}$ & $\begin{array}{l}-0.006 \\
(0.004)\end{array}$ & $\begin{array}{c}0.009 * * \\
(0.004)\end{array}$ & $\begin{array}{c}0.009 * * * \\
(0.003)\end{array}$ \\
\hline Sep & $\begin{array}{c}-0.004 * * * \\
(0.001)\end{array}$ & $\begin{array}{c}-0.007 * * \\
(0.004)\end{array}$ & $\begin{array}{c}0.003 \\
(0.004)\end{array}$ & $\begin{array}{c}0.006 * * \\
(0.003)\end{array}$ \\
\hline Oct & $\begin{array}{c}-0.002^{*} \\
(0.001)\end{array}$ & $\begin{array}{c}-0.007^{*} \\
(0.004)\end{array}$ & $\begin{array}{l}-0.000 \\
(0.004)\end{array}$ & $\begin{array}{c}0.011 * * * \\
(0.003)\end{array}$ \\
\hline Nov & $\begin{array}{l}-0.000 \\
(0.001)\end{array}$ & $\begin{array}{l}-0.002 \\
(0.004)\end{array}$ & $\begin{array}{l}-0.004 \\
(0.004)\end{array}$ & $\begin{array}{c}0.009 * * * \\
(0.003)\end{array}$ \\
\hline Dec & $\begin{array}{c}0.001 \\
(0.001)\end{array}$ & $\begin{array}{c}0.002 \\
(0.004)\end{array}$ & $\begin{array}{c}0.002 \\
(0.004)\end{array}$ & $\begin{array}{c}0.012 * * * * \\
(0.003)\end{array}$ \\
\hline N kids & $3,701,062$ & 559,420 & 419,239 & 233,654 \\
\hline ADHD prev (\%) & 4.6 & 7.15 & 6.04 & 5.25 \\
\hline $\begin{array}{l}\text { p-value } \\
\text { (June=July) }\end{array}$ & $<0.0001$ & 0.519 & 0.484 & 0.968 \\
\hline $\begin{array}{l}\text { p-value (diff } \\
\text { between months } \\
\text { around cutoff) }\end{array}$ & $<0.0001$ & 0.001 & 0.4696 & 0.0001 \\
\hline
\end{tabular}

Notes: Coefficients after OLS estimation. Pooling all data years (2008-2011) and cohorts in assigned grade levels 3 to 8. Cohorts who are directly affected by shifts in cutoffs (and are thus larger than normal cohorts) excluded. $p$ values in last two line for two hypotheses tests: equality between June and July coefficients and between coefficients around cutoff date in respective column. 
Table 4: Descriptive Statistics - Districts

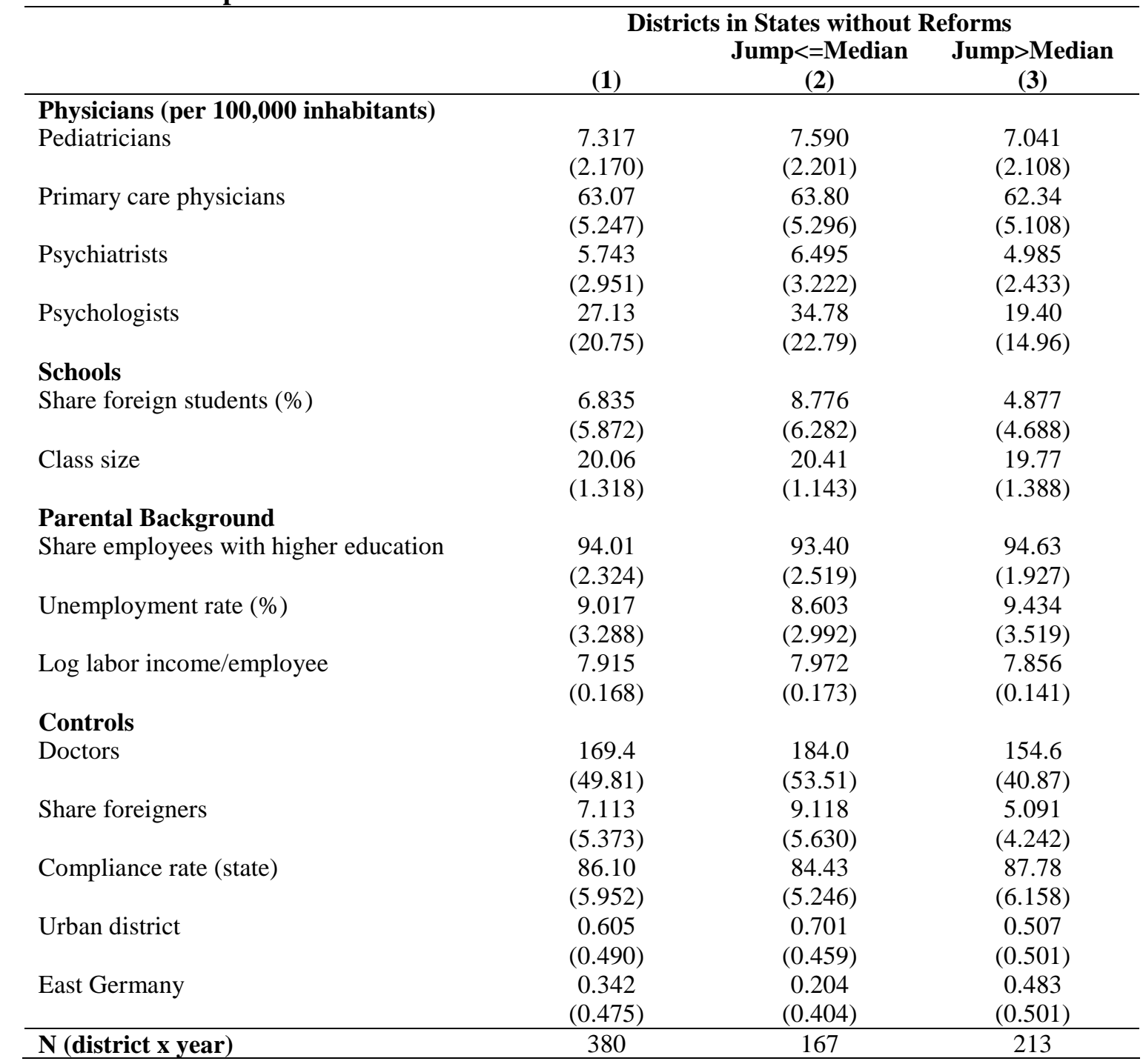

Notes: Means (standard deviations) weighted by number of kids in district. Number of observations for class size column (1): 376, (2): 163, (3): 213 
Table 5: Explaining jumps around cutoff dates across districts

\begin{tabular}{|c|c|c|c|c|}
\hline $\begin{array}{l}\text { Dep. var.: Change in ADHD prevalence } \\
\text { around age cutoff (in p.p.) }\end{array}$ & (1) & (2) & (3) & (4) \\
\hline \multicolumn{5}{|l|}{ Physicians (per 100,000 inhabitants) } \\
\hline Pediatricians & $\begin{array}{l}-0.020 \\
(0.044)\end{array}$ & $\begin{array}{l}-0.053 \\
(0.047)\end{array}$ & $\begin{array}{c}-0.007 \\
(0.127)\end{array}$ & $\begin{array}{l}-0.033 \\
(0.126)\end{array}$ \\
\hline Primary care physicians & $\begin{array}{l}-0.020 \\
(0.014)\end{array}$ & $\begin{array}{l}-0.004 \\
(0.014)\end{array}$ & $\begin{array}{r}-0.050+ \\
(0.034)\end{array}$ & $\begin{array}{r}-0.053+ \\
(0.036)\end{array}$ \\
\hline Psychiatrists & $\begin{array}{l}-0.044 \\
(0.033)\end{array}$ & $\begin{array}{c}-0.085^{*} \\
(0.048)\end{array}$ & $\begin{array}{c}-0.026 \\
(0.094)\end{array}$ & $\begin{array}{l}-0.059 \\
(0.094)\end{array}$ \\
\hline Psychologists & $\begin{array}{l}-0.015^{* *} \\
(0.008)\end{array}$ & $\begin{array}{l}-0.021 * * \\
(0.010)\end{array}$ & $\begin{array}{l}-0.044 \\
(0.032)\end{array}$ & $\begin{array}{l}-0.049 \\
(0.034)\end{array}$ \\
\hline \multicolumn{5}{|l|}{ Schools } \\
\hline Share foreign students (\%) & $\begin{array}{c}0.110 * * \\
(0.045)\end{array}$ & $\begin{array}{c}0.104 * * \\
(0.043)\end{array}$ & $\begin{array}{c}0.191+ \\
(0.119)\end{array}$ & $\begin{array}{c}0.186+ \\
(0.124)\end{array}$ \\
\hline Class size & & & & $\begin{array}{l}0.224 * \\
(0.133)\end{array}$ \\
\hline \multicolumn{5}{|l|}{ Parental Background } \\
\hline Share employees with higher education (\%) & $\begin{array}{c}0.004 \\
(0.038)\end{array}$ & $\begin{array}{c}0.036 \\
(0.050)\end{array}$ & $\begin{array}{c}0.406 * * \\
(0.192)\end{array}$ & $\begin{array}{l}0.331 * \\
(0.193)\end{array}$ \\
\hline Unemployment rate $(\%)$ & $\begin{array}{l}-0.019 \\
(0.027)\end{array}$ & $\begin{array}{c}-0.068+ \\
(0.041)\end{array}$ & $\begin{array}{c}0.053 \\
(0.090)\end{array}$ & $\begin{array}{c}0.079 \\
(0.088)\end{array}$ \\
\hline Log labor income & $\begin{array}{c}0.484 \\
(0.815)\end{array}$ & $\begin{array}{c}0.461 \\
(1.314)\end{array}$ & $\begin{array}{l}6.090 * \\
(3.236)\end{array}$ & $\begin{array}{l}6.178^{*} \\
(3.153)\end{array}$ \\
\hline Controls & Yes & Yes & Yes & Yes \\
\hline State F.E. & No & Yes & - & - \\
\hline Distr. F.E. & No & No & Yes & Yes \\
\hline R2 & 0.272 & 0.354 & 0.770 & 0.769 \\
\hline $\mathbf{N}$ (district $\mathrm{x}$ year $)$ & 380 & 380 & 380 & 376 \\
\hline
\end{tabular}

Notes: Dep var=cutoff jump (averaged across assigned grades 3-8) in p.p. in years 2008-2011. Standard Errors clustered at district level in parentheses. All specifications include year fixed effects. Controls include districtlevel share of foreigners, physicians per 100,000 inhabitants, dummies for urban districts, for East Germany, and the state-level compliance rate. The sample excludes states that had cutoff date reforms. In column (4) one district (Hamburg) is excluded because information on class size is not available for this district. 
Table 6: Robustness Analysis: Excluding States with general health screenings in school

\begin{tabular}{|c|c|c|c|c|}
\hline $\begin{array}{l}\text { Dep. var.: Change in ADHD prevalence } \\
\text { around age cutoff (in p.p.) }\end{array}$ & (1) & (2) & (3) & (4) \\
\hline \multicolumn{5}{|l|}{ Physicians (per 100,000 inhabitants) } \\
\hline \multirow[t]{2}{*}{ Pediatricians } & $-0.100 *$ & -0.072 & 0.018 & -0.027 \\
\hline & $(0.051)$ & $(0.086)$ & $(0.184)$ & $(0.174)$ \\
\hline \multirow{2}{*}{ Primary care physicians } & $-0.032 * *$ & -0.024 & -0.018 & -0.019 \\
\hline & $(0.015)$ & $(0.015)$ & $(0.039)$ & $(0.042)$ \\
\hline \multirow[t]{2}{*}{ Psychiatrists } & 0.018 & -0.017 & -0.001 & -0.041 \\
\hline & $(0.030)$ & $(0.051)$ & $(0.127)$ & $(0.132)$ \\
\hline \multirow[t]{2}{*}{ Psychologists } & $-0.029 * * *$ & $-0.025 * *$ & -0.056 & -0.068 \\
\hline & $(0.010)$ & $(0.011)$ & $(0.041)$ & $(0.045)$ \\
\hline \multicolumn{5}{|l|}{ Schools } \\
\hline \multirow[t]{2}{*}{ Share foreign students $(\%)$} & $0.137 * * *$ & $0.120 * * *$ & $0.277 * *$ & $0.282 * *$ \\
\hline & $(0.040)$ & $(0.039)$ & $(0.115)$ & $(0.116)$ \\
\hline \multirow[t]{2}{*}{ Class size } & & & & $0.251 *$ \\
\hline & & & & $(0.145)$ \\
\hline \multicolumn{5}{|l|}{ Parental Background } \\
\hline \multirow[t]{2}{*}{ Share employees with higher education (\%) } & -0.010 & 0.024 & $0.578 * *$ & $0.538 * *$ \\
\hline & $(0.039)$ & $(0.048)$ & $(0.249)$ & $(0.240)$ \\
\hline \multirow[t]{2}{*}{ Unemployment rate (\%) } & $-0.121 * * *$ & $-0.097 *$ & 0.096 & 0.138 \\
\hline & $(0.039)$ & $(0.051)$ & $(0.114)$ & $(0.111)$ \\
\hline \multirow[t]{2}{*}{ Log labor income/employee } & $-1.657 *$ & -1.228 & 2.224 & 4.272 \\
\hline & $(0.891)$ & $(1.325)$ & $(3.878)$ & $(4.179)$ \\
\hline Controls & Yes & Yes & Yes & Yes \\
\hline State F.E. & No & Yes & No & No \\
\hline Distr. F.E. & No & No & Yes & Yes \\
\hline $\mathbf{R 2}$ & 0.271 & 0.307 & 0.725 & 0.727 \\
\hline $\mathbf{N}$ (district $x$ year) & 200 & 200 & 200 & 196 \\
\hline
\end{tabular}

Notes: Dep var=cutoff jump (averaged across grades 3-8) in p.p. in years 2008-2011. Standard Errors clustered at district level in parentheses. All specifications include year fixed effects. Controls include district-level share of foreigners, unemployment rate, physicians per 100,000 inhabitants, dummies for urban districts, for East Germany, and the state-level compliance rate.. In columns (4) one district (Hamburg) is excluded because information on class size is not available for this district. 


\section{Appendix}

\section{A. Comparison of ADHD Prevalence Rates across Data Sources}

A study published in 2013 by one of the largest health insurance plans in the SHI (Barmer GEK) presents ADHD diagnosis prevalence rates for children aged 5-9 and 10-14 in the years 2008 through 2011. The data contain information on all children insured with Barmer GEK, irrespective of their health care use in the given year. The results presented in the study rely on only one valid diagnosis to calculate ADHD diagnosis prevalence. To compare ADHD prevalence in our data to the published results, Figure A.1 displays diagnoses prevalence based on one diagnosis in our data in addition to the baseline measures using two diagnoses. As Figure A.1 suggests, the rates based on one diagnoses are almost identical across the two data sources for the different age groups and data years, suggesting that even though we only observe children if they visited a doctor at least once in our data our approach does not vastly overestimate ADHD prevalence in Germany.

Figure A.1 ADHD Prevalence in Germany - Baseline and Comparison Data

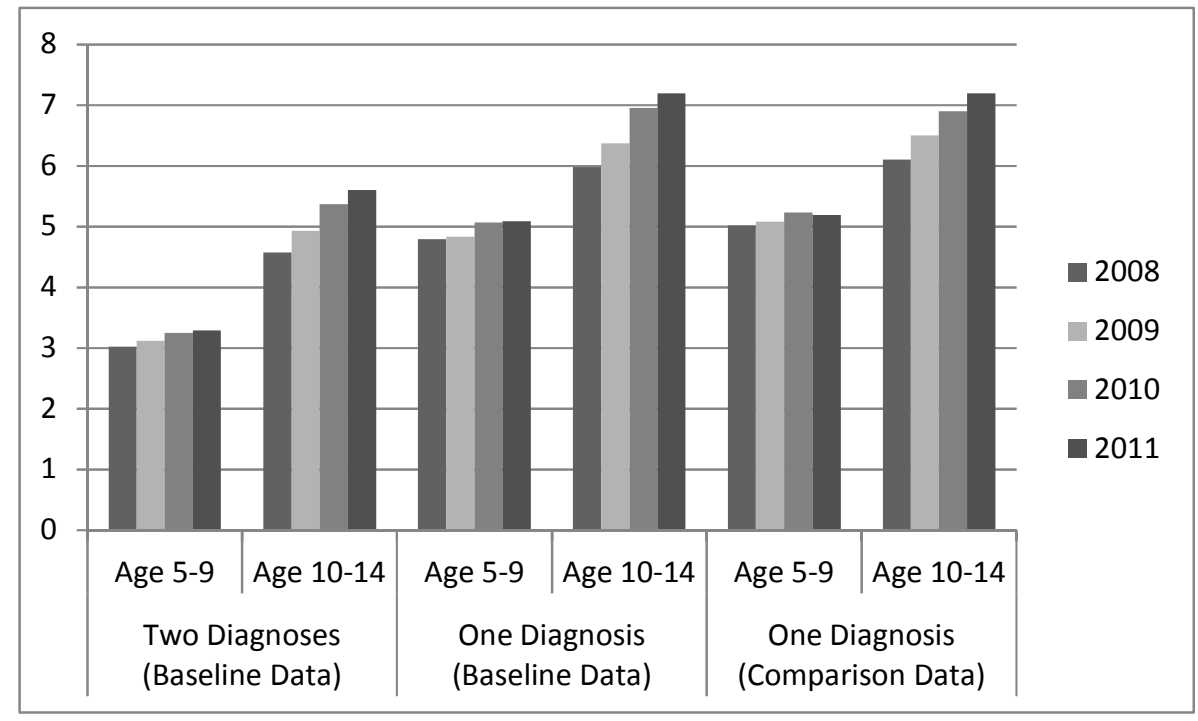




\section{B. Additional Figures and Tables}

Figure B.1: ADHD prevalence across birth months in states with different school entry cutoffs.
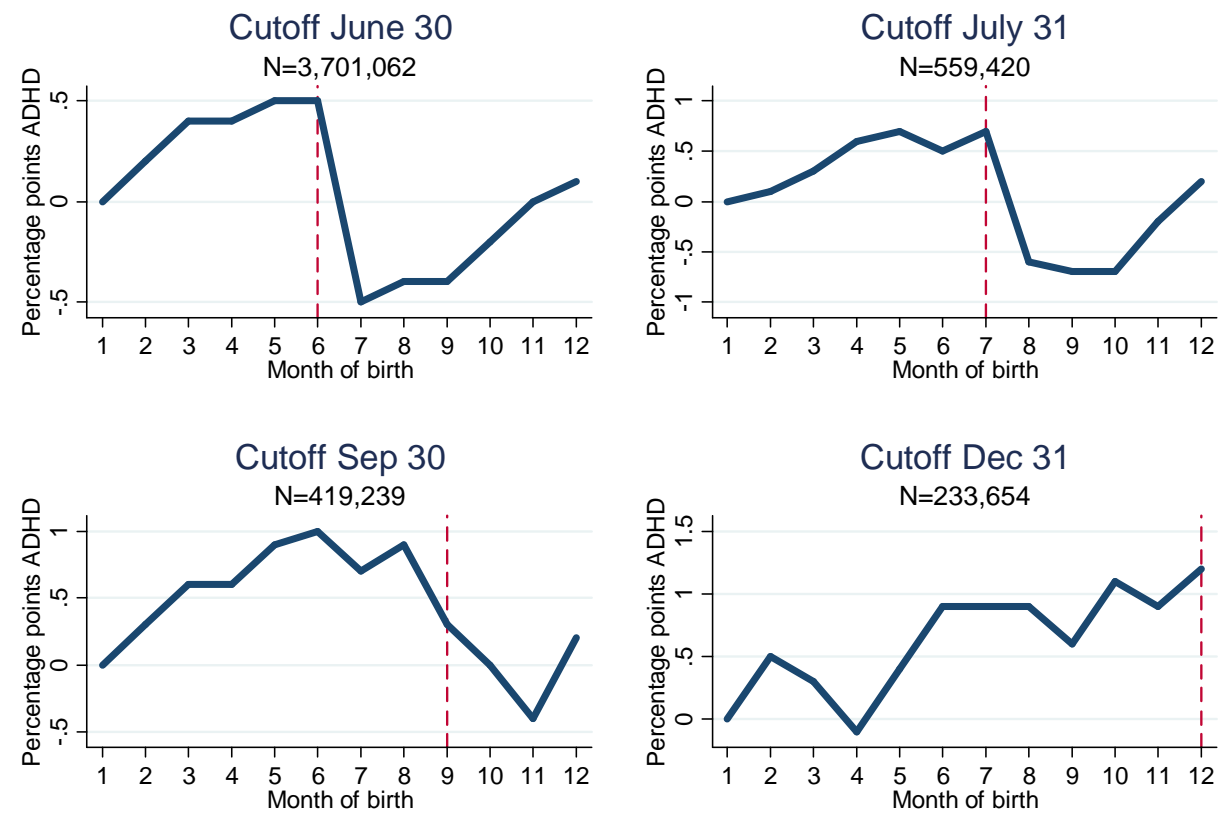

Figures show the difference in ADHD prevalence compared to January 


\section{Figure B.2: Percent of children treated for injuries, among those without ADHD diagnosis}

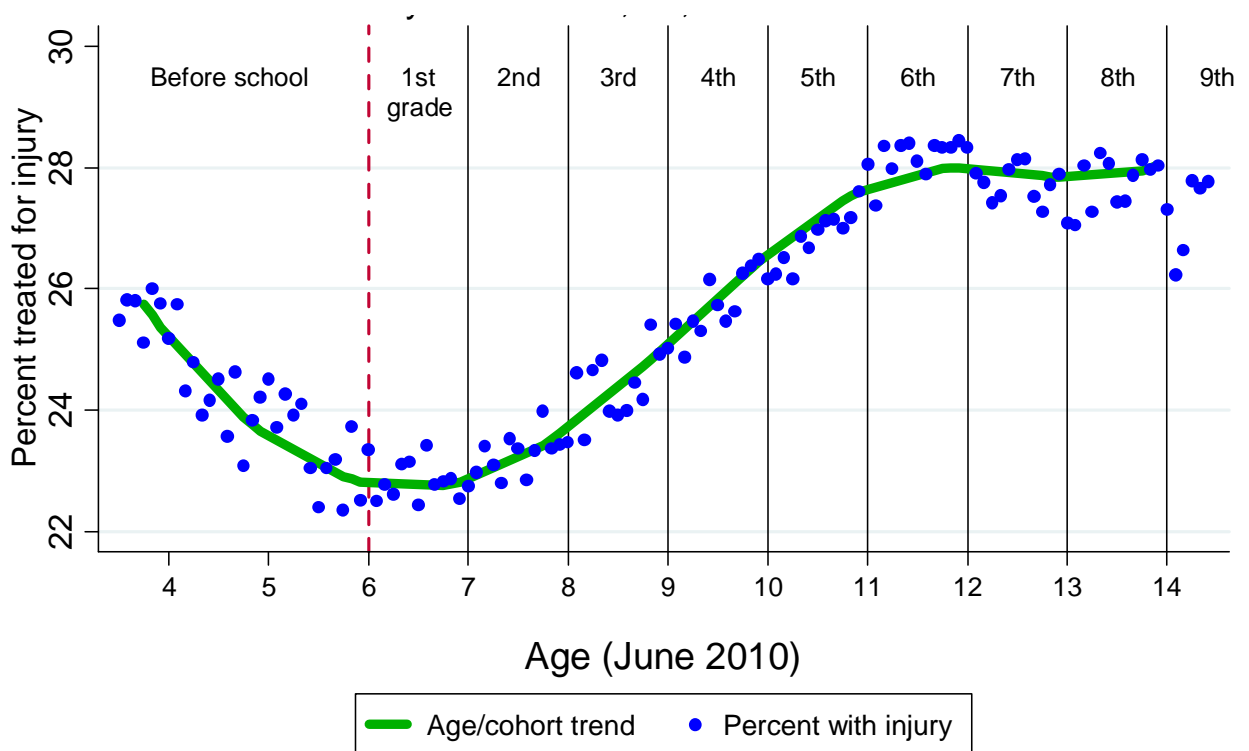

Notes: This figure shows the percent of school children without ADHD diagnosis treated for injuries in 2010 by children's age, measured in months as of June 2010. The sample includes all states with June 30 as school entry cutoffs and without reforms in the cutoff. $\mathrm{N}=1,626,712$. Average prevalence is $25.5 \%$. The dashed line indicates the assigned school start (i.e. those who are of age 6 or above in June 2010 are supposed to enter school). The solid lines show the respective assigned cutoffs between grades at higher ages. 
Figure B.3: Average jumps in ADHD prevalence around cutoff (pooled 2008-2011)

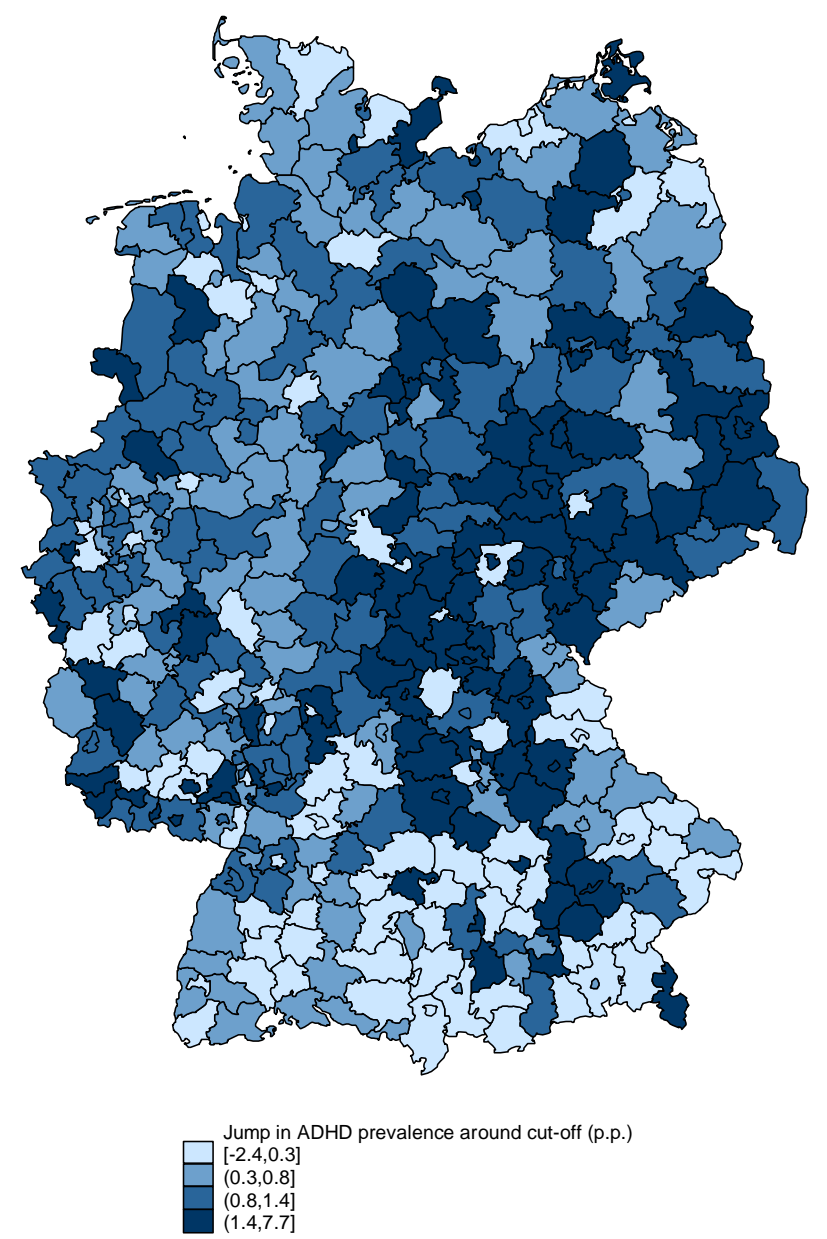

Notes: Pooling jumps across grades 3-8. Due to timing of reforms, included grade levels vary for states with cutoff date reforms. 


\section{Appendix Table 1: Cutoff Dates Across States and Years}

\begin{tabular}{|c|c|c|c|c|c|c|c|c|c|c|}
\hline & Until 2002 & 2003 & 2004 & 2005 & 2006 & 2007 & 2008 & 2009 & 2010 & 2011 \\
\hline \multicolumn{11}{|c|}{ States without Reform of Cutoff Date } \\
\hline Bremen & June 30 & $\ldots$ & $\ldots$ & $\ldots$ & $\ldots$ & $\ldots$ & $\ldots$ & $\ldots$ & $\ldots$ & June 30 \\
\hline Hamburg & June 30 & $\cdots$ & $\cdots$ & $\cdots$ & $\ldots$ & $\cdots$ & $\cdots$ & $\cdots$ & $\cdots$ & June 30 \\
\hline Hesse & June 30 & $\cdots$ & $\cdots$ & $\cdots$ & $\cdots$ & $\cdots$ & $\cdots$ & $\cdots$ & $\cdots$ & June 30 \\
\hline $\begin{array}{l}\text { Mecklenburg West- } \\
\text { Pommerania }\end{array}$ & June 30 & $\ldots$ & $\cdots$ & $\ldots$ & $\ldots$ & $\cdots$ & $\ldots$ & $\ldots$ & $\ldots$ & June 30 \\
\hline Saarland & June 30 & $\cdots$ & $\cdots$ & $\cdots$ & $\cdots$ & $\cdots$ & $\cdots$ & $\cdots$ & $\cdots$ & June 30 \\
\hline Saxony & June 30 & $\cdots$ & $\cdots$ & $\cdots$ & $\cdots$ & $\cdots$ & $\cdots$ & $\ldots$ & $\cdots$ & June 30 \\
\hline Saxony -Anhalt & June 30 & $\cdots$ & $\cdots$ & $\ldots$ & $\ldots$ & $\cdots$ & $\cdots$ & $\ldots$ & $\cdots$ & June 30 \\
\hline Schleswig-Holstein & June 30 & $\cdots$ & $\cdots$ & $\cdots$ & $\cdots$ & $\cdots$ & $\cdots$ & $\cdots$ & $\cdots$ & June 30 \\
\hline \multicolumn{11}{|c|}{ States with reform of Cutoff Date } \\
\hline Baden-Wuerttemberg & June 30 & $\cdots$ & $\cdots$ & July 31 & Aug 31 & Sep 30 & $\ldots$ & $\cdots$ & $\cdots$ & Sep 30 \\
\hline Bavaria & June 30 & $\cdots$ & $\cdots$ & July 31 & Aug 31 & Sep 30 & Oct 31 & Nov 30 & Sep 30 & Sep 30 \\
\hline Berlin & June 30 & $\cdots$ & $\cdots$ & Dec 31 & $\cdots$ & $\ldots$ & $\cdots$ & $\ldots$ & $\cdots$ & Dec 31 \\
\hline Brandenburg & June 30 & $\cdots$ & $\cdots$ & Sep 30 & $\ldots$ & $\ldots$ & $\cdots$ & $\ldots$ & $\ldots$ & Sep 30 \\
\hline Lower Saxony & June 30 & $\cdots$ & $\cdots$ & $\cdots$ & $\ldots$ & $\cdots$ & $\ldots$ & $\cdots$ & July 31 & Aug 31 \\
\hline North-Rhein Westphalia & June 30 & $\cdots$ & $\cdots$ & $\cdots$ & $\cdots$ & July 31 & $\cdots$ & Aug 31 & $\cdots$ & Sep 30 \\
\hline Rhineland-Palatinate & June 30 & $\cdots$ & $\cdots$ & $\ldots$ & $\ldots$ & $\cdots$ & Aug 31 & $\ldots$ & $\cdots$ & Aug 31 \\
\hline Thuringia & June 30 & July 31 & $\cdots$ & $\ldots$ & $\ldots$ & $\ldots$ & $\cdots$ & $\ldots$ & $\cdots$ & July 31 \\
\hline
\end{tabular}


Appendix Table 2: Additional Data Sources

\begin{tabular}{|c|c|c|}
\hline Variable & Geo. Level & Data Source \\
\hline \multicolumn{3}{|l|}{ Supply of Physicians } \\
\hline Pediatricians/100,000 inhabitants & District level & INKAR $^{\mathrm{a}}$ \\
\hline General Practitioners/100,000 inhabitants & District level & INKAR \\
\hline Psychotherapists/100,000 inhabitants & District level & INKAR \\
\hline Psychologists/100,000 inhabitants & District level & INKAR \\
\hline Physicians/100,000 inhabitants & District level & INKAR \\
\hline \multicolumn{3}{|l|}{ Socio-Economic Background } \\
\hline Share employees with higher education (\%) & District level & INKAR \\
\hline Unemployment rate $(\%)$ & District level & INKAR \\
\hline Share foreigners $(\%)$ & District level & INKAR \\
\hline \multicolumn{3}{|l|}{ School Environment } \\
\hline Average class size (students/class) & District level & Statistical services of the different German states \\
\hline Share foreign students in schools (\%) & District level & INKAR \\
\hline Compliance rate with cutoff dates $(\%)$ & State level & German Federal Statistical Office, Fachserie 11, Reihe 1 \\
\hline
\end{tabular}

Notes: $\left({ }^{\mathrm{a}}\right)$ INKAR (Indikatoren und Karten zur Raum- und Stadtentwicklung) is a service provided by the German Federal Institute for Research on Building, Urban Affairs and Spatial Development (BBSR) (see www.inkar.de). 


\section{CENTRE FOR ECONOMIC PERFORMANCE \\ Recent Discussion Papers}

$1393 \quad \begin{aligned} & \text { Yatang Lin } \\ & \text { Yu Qin } \\ & \text { Zhuan Xie }\end{aligned}$

1392 Robin Naylor Jeremy Smith Shqiponja Telhaj

1391 Marc Fleurbaey Hannes Schwandt

1390 Benjamin R. Handel Jonathan T. Kolstad Johannes Spinnewijn

1389 Kilian Huber

1388 Francesco Caselli Miklos Koren Milan Lisicky Silvana Tenreyro

1387 Hannes Schwandt Janet Currie

1386 Marta De Philippis

1385 Ferdinando Monte Stephen J. Redding Esteban Rossi-Hansberg

1384 Tito Boeri Juan Francisco Jimeno

1383 Sarah Flèche
International Technology Transfer and Domestic Innovation: Evidence from the High-Speed Rail Sector in China

Graduate Returns, Degree Class Premia and Higher Education Expansion in the UK

Do People Seek To Maximize Their Subjective Well-Being?

Information Frictions and Adverse Selection: Policy Interventions in Health Insurance Markets

The Persistence of a Banking Crisis

Diversification through Trade

Short and Long-Term Effects of Unemployment on Fertility

Multitask Agents and Incentives: The Case of Teaching and Research for University Professors

Commuting, Migration and Local Employment Elasticities

The Unbearable Divergence of Unemployment in Europe

Distaste for Centralization: Evidence from a Quasi-Natural Experiment in Switzerland 
1382 Johannes Boehm

1381 Andrew B. Bernard Swati Dhingra

1380 Warn N. Lekfuangfu

Nattavudh Powdthavee

Andrew E. Clark

George Ward

1379 Scott R. Baker

Nicholas Bloom

Steven J. Davis

1378 Holger Breinlich

Volker Nocke

Nicolas Schutz

1377 Kalina Manova

Zhihong Yu

1376 Jordi Blanes i Vidal

Tom Kirchmaier

1375 Fabrice Defever

Christian Fischer

Jens Suedekum

1374 Brian Bell

Rui Costa

Stephen Machin

1373 Christos Genakos

Costas Roumanias

Tommaso Valletti

1372 Shaun Larcom

Ferdinand Rauch

Tim Willems
The Impact of Contract Enforcement Costs on Outsourcing and Aggregate Productivity

Contracting and the Division of the Gains from Trade

Early Maternal Employment and Noncognitive Outcomes in Early Childhood and Adolescence: Evidence from British Birth Cohort Data

Measuring Economic Policy Uncertainty

Merger Policy in a Quantitative Model of International Trade

How Firms Export: Processing vs. Ordinary Trade With Financial Frictions

The Effect of Police Response Time on Crime Detection

Relational Contracts and Supplier Turnover in the Global Economy

Crime, Compulsory Schooling Laws and Education

Loss Aversion on the Phone

The Benefits of Forced Experimentation:

Striking Evidence from the London

Underground Network 